Federal Reserve Bank of Dallas

Globalization and Monetary Policy Institute

Working Paper No. 186

http:// www.dallasfed.org/ assets/ documents/ institute/ wpapers/2014/ 0186.pdf

\title{
The Domestic Segment of Global Supply Chains In China under State Capitalism*
}

\author{
Heiwai Tang \\ Johns Hopkins University and CESIfo \\ Fei Wang \\ University of International Business and Economics \\ Zhi Wang \\ United States International Trade Commission
}

June 2014

\begin{abstract}
This paper proposes methods to incorporate firm heterogeneity in the standard IO-table based approach to portray the domestic segment of global value chains in a country. Using Chinese firm census data for both manufacturing and service sectors, along with constrained optimization techniques, we split the conventional IO table into sub-accounts, which are used to estimate direct and indirect domestic value added in exports of different types of firm. We find that in China, both state-owned enterprises (SOEs) and small and medium domestic private enterprises (SMEs) have much higher shares of indirect exports and ratios of value-added exports to gross exports (VAX), compared to foreign-invested and large domestic private firms. Based on IO tables for both 2007 and 2010, we find increasing VAX ratios for all firm types, particularly for SOEs. By extending the method proposed by Antràs et al. (2012), we find that SOEs are consistently more upstream while SMEs are consistently more downstream within industries. These findings suggest that SO Es still play an important role in shaping China's exports.
\end{abstract}

JEL codes: F1, C67, C82

\footnotetext{
* Heiwai Tang, School of Advanced International Studies, Johns Hopkins University, 1717 Massachusetts Avenue NW, Suite 709, Washington, DC 20036. 202-663-5679. hwtang@jhu.edu. Fei Wang, School of International Trade and Economics, University of International Business and Economics, P.O. Box 119, No. 10, Huixin Dongjie, Beijing, 100029, China. Zhi Wang, United States International Trade Commission, 500 E Street SW, Washington, DC 20436. 202-205-3245 zhi.wang@usitc.gov. We thank Russell Hillberry and participants at various seminars and conferences for insightful discussions and suggestions. We thank XiaoPeng Yin for his contribution in the initial stage of this project. Heiwai Tang thanks the World Bank for financial support. The views in this paper are those of the authors and do not necessarily reflect the views of the U.S. International Trade Commission, the Federal Reserve Bank of Dallas or the Federal Reserve System.
} 


\section{Introduction}

The stellar export growth of China was often attributed to its low labor costs, trade liberalization, and policies that promote processing trade and foreign direct investment (FDI) (Branstetter and Lardy, 2006). The way that China integrated itself with the rest of the world resembles a typical catch-up story in East Asia - by first participating in the downstream of global value chains (GVCs) and gradually moving upstream. Concurrently, when China was globalizing, many state-owned enterprises (SOEs), especially those that are small in downstream sectors, were privatized or let go. ${ }^{5}$ Years of privatization gave room to entry of the more productive private firms, which have been shown to be an important driver of the drastic productivity growth in China (Brandt, et al., 2012; Zhu, 2012). While the shares of SOEs in China's total value added, employment, and gross exports have been declining substantially, recent evidence shows that SOEs still monopolize the key upstream and non-tradable sectors. SOEs also appeared to gain increasing prevalence and profits in the Chinese economy in recent years, especially after the global financial crises in 2008-2009. ${ }^{6}$

Against this backdrop, this paper aims to answer the following questions: Which sectors did SOEs still have a prominent presence? How did the sectoral distribution of the prevalence of SOEs and its evolution in recent years shape the trade patterns of other firms, as well as their own? How did this sectoral distribution affect the intra-national trade and income distribution in China when the country is globalizing? To answer these questions, we first propose methods to split a conventional input-output (IO) table into sub-accounts that feature input-output linkages between different firm types. Specifically, we use firm-level data to group firms based on their key characteristics, which include export intensity, value-added to sales ratio, and ownership type. We then estimate the coefficients of the split tables using constrained optimization techniques, based on known statistics from firm census data for both manufacturing and service sectors, as well as detailed trade statistics. We can then estimate the volume of inter-industry trade flows between different types of firms within China and quantify the importance of different channels of indirect (value added) exports. While the paper focuses on SOEs, our methods are general enough to portray the domestic input-output linkages of Chinese exports, and can be applied to assess value-added exports by firm type in other countries. Our results add to the "value added trade" literature, which has focused mainly on the relative contribution of different countries to GVC, by formally portraying the composition and dynamics of the domestic segment of GVC in a large developing country.

\footnotetext{
${ }^{5}$ The 15th Congress of the Chinese Communist Party in 1997 marked the watershed of China's economic reforms. The Congress formally sanctioned ownership reforms of the state-owned firms and also legalized the development of private enterprises.

${ }^{6}$ See Zhu (2012) for a comprehensive review of China's growth experience and the decline role of SOEs. See He, et al. (2012) for a study showing the continuing importance of SOEs in shaping the Chinese economy. Wang et al. (2012) develop a theoretical model to rationalize the rising profits of surviving SOEs.
} 
Specifically, we split the conventional IO tables of China for 2007 and 2010 into transactions between six groups of firms, defined by ownership type and firm size, namely large SOEs (LSOE), small and medium SOEs (SSOE), large foreign invested enterprises (LFIE), small and medium FIEs (SFIE) large private (LP), and small and medium private enterprises (SME). Based on the six-group split of the IO tables, we report our results for four types: SOEs, FIEs, LPs, and SMEs. We find that SOEs' value added (VA) exports are significantly larger than their gross exports, contrasting with the common finding of low value added in Chinese exports (Chen et al., 2012; Koopman, et al. 2012). Specifically, the value added to gross export (VAX) ratio of SOEs is estimated to be 1.2 in 2007 and 1.8 in 2010, compared to around 0.35 for FIEs in both years. These results contrast with the findings in developed countries, such as the United States, where large firms tend to have lower VAX. Among private firms, large firms' VAX is around 0.7 for both years, while SMEs' VAX exceeded 1 for both years, and increased from slightly above 1 in 2007 to 1.3 in 2010.

Another advantage of splitting the conventional IO table into sub-accounts based on available micro data is that we can analyze trade between different firm types in the domestic segment of GVC in great detail. About $80 \%$ of SOEs' VA exports are indirect (exporting through other firms) in 2007, which increased further in 2010. Of these indirect exports, about 40\% is through small firms, both domestic and foreign. These findings suggest that although SOEs' direct participation in exporting has been low, its actual participation and impact on China's exports have remained high and have been overlooked. Similar to SOEs, LPs and SMEs both have a large share of indirect VA exports, though LPs have a much lower VAX. On the other hand, FIEs tend to export more directly.

We also investigate the reasons behind the high indirect export participation for both SOEs and SMEs. Turning to the industry distribution of indirect exports by firm type, we find that SOEs' indirect exports are due to their prevalence in upstream or non-tradable industries, such as energy and mining; metal and non-metallic mineral extraction; electricity; gas and water supply; and the financial sector. This may not be surprising, since we also observe high indirect export shares in similar industries for large domestic private firms. One can argue that this could also be true in other countries, almost by definition. However, what we intend to show is that SOEs, not only large firms, have been dominating the upstream of the domestic segment of GVC in China, possibly due to the sequential pattern of privatization. While the political economy factors behind this pattern are beyond the scope of this paper, we believe that a systematic documentation can already provide important insights for understanding China's past and future economic growth. The conventional view is that China's export growth is largely driven by the dynamic labor-intensive private sector, especially the foreign-dominated processing trade sector. Our findings add to this conventional view by showing that SOEs, through their protected position in the upstream, have 
been playing an important role in shaping Chinese export patterns and performance. Based on information from the IO tables for only two years (2007 and 2010), we find evidence of significant increases in SOEs' VAX ratio, indirect to direct VA export ratio, and share of VA in aggregate exports. These findings have important policy implications. For instance, to the extent that SOEs are less productive than non-state firms (e.g., Zhu, 2012), a deeper privatization of SOEs or lower entry barriers in upstream industries may increase the efficiency of direct exporters in the downstream, which in turn increases the speed of upgrading of Chinese exporters’ along GVC.

We find that SOEs' dominance in upstream industries is observed not only between industries but also within industries. This fact is established by measuring an industry's upstreamness by firm ownership type, based on the methods proposed by Antras et al. (2012) and Fally (2012). Using the estimated coefficients of our extended IO table, we measure upstreamness by industry and firm type. Based on the IO table for 2007, Fig. 5 shows that SOEs tend to be more upstream than non-state firms within an industry (see Fig. 8). Figs. 4 and 5 further confirm that SOEs have larger output and export shares in upstream industries, while SMEs exhibit the opposite pattern (see Figs. 6-7). These findings suggest that SOE's prevalence in upstream industries can be a potential explanation for their high VAX, compared to other firms. Furthermore, we find that the upstreamness measure increases for more than two-third of the 40 sectors from 2007 to 2010 (see Fig. 9). The increase was across the board for all ownership types, suggesting that Chinese firms are "moving up” in GVC, an opposite pattern observed for the U.S. (Fally, 2012).

Although SMEs are similar to SOEs in the sense that they also have high value added and indirect export ratios, the sources of the similarities appear to be quite different. In addition to the fact that SMEs are more likely to export through other private firms, their upstreamness measures are generally lower than those of other types of firms within an industry (see Fig. 8). These findings suggest that the high VAX and indirect export share of SMEs are probably due to their higher propensity to sell intermediate inputs and services to other large firms that eventually export, not due to their relative upstream position in the domestic input-output network like SOEs. The findings also highlight a subtle distinction between high upstreamness and high indirect export shares of an industry.

Did the increase in SOEs' VAX lead to rising profits for the upstream SOEs, as some recent studies claim? Using our split IO table, we can examine how much profit in the Chinese economy could be attributed to exports, both directly and indirectly, and through which type of firms. We find that while total export-related profits declined from 2007 to 2010, the decline fell largely on SMEs. On the other hand, SOEs, FIEs, and LPs all experienced an increase in export-related profits between 2007 and 2010. 
However, unlike the sharp increase in VAX for SOEs, we find no evidence that SOEs' export-related profits increased the most. In other words, rising SOEs' value added exports in recent years did not automatically translate into higher SOEs’ profits.

Our paper makes several contributions to the literature. First, it adds to the growing literature on production fragmentation across national borders (e.g., Hummels, Ishii, and Yi, 2001, Johnson and Noguera, 2012a, 2012b; Koopman, Wang, and Wei, 2012; Koopman, Wang, and Wei, 2014). The focus of that literature has been on the relative shares of domestic versus foreign value added in international trade. While establishing these facts and providing accurate measures of trade flows is urgently needed in the increasingly globalized world, the composition and dynamics of the domestic segment of GVC have not been subject to the same level of scrutiny. In particular, understanding how trade liberalization affects intra-national trade between industries and in turn shapes the reallocation of resources and across industries and firms is important for designing development policies. Our paper takes a first step by analyzing intra-national trade between different firm types, focusing on the roles of SOEs and SMEs in China.

Related to the value-added trade literature, our approach extends the IO-table based approach to incorporate the "new new" trade literature that emphasizes firm heterogeneity. In reality, firms differ substantially in their export intensity, import intensity, and position of participation along GVC. Other characteristics such as ownership structure (domestic/foreign, private/public), location, size can also directly affect the way firms respond to trade liberalization and other economic shocks. The usual method that relies on the aggregate IO tables ignores most of the underlying firm heterogeneity. The lack of information on between-firm transactions in the micro data also restricts the construction of IO tables by firm type. Moreover, a widely recognized drawback of using IO tables to measure VAX is the assumption that firms within an industry use the same technology for production. Proportionality assumptions are often made in order to distribute imports into different final uses and different source countries, as information on bilateral trade between suppliers and users is generally not available at the country-industry level. ${ }^{7}$ Our paper provides a method to reduce the measurement bias due to heterogeneity in export and import intensities across firm sizes and ownership types.

Our paper also contributes to the literature on the determinants of firm export participation and other indirect export channels. Research in international trade shows that only a small fraction of enterprises,

\footnotetext{
7 These assumptions have been shown to lead to substantial biases in the estimation of countries' value added, factor content of trade, and our general inference of the impact of trade on countries' macro-economy (e.g., Puzzello, 2012). For instance, De La Cruz et al. (2011) and Koopman, Wang and Wei (2012) show that by allowing different imported material intensities for processing and non-processing exporters, the estimated foreign value added ratio in aggregate exports from both China and Mexico increases significantly.
} 
usually large, directly participate in international trade (e.g., Bernard, et al., 2007). ${ }^{8}$ The standard argument is that exporting is usually associated with high fixed costs and only large (productive) firms can make sufficiently high export revenue to amortize them. However, many non-exporters may engage in international trade indirectly, through wholesalers and other intermediaries, as well as by providing intermediate inputs and services to exporters of all sizes, particularly large multinationals. While the first channel has received a lot of attention in the recent literature (e.g., Bernard et al., 2010 and Ahn et al., 2012), the second channel has not received the deserved attention, partly due to the lack of data on inter-firm transactions within a country. ${ }^{9}$ Our paper provides a methodology that combine firm-level and industry-level data to quantify the volume of indirect exports, and through which channel "non-exporters" export indirectly.

Finally, our paper relates to the large literature on the role of SOEs in shaping the Chinese economy (e.g., Brandt et al, 2012; Zhu, 2012). As discussed before, the conventional view is that the Chinese government has been reducing the share of SOEs in the economy. Privatization of SOEs is often attributed to China's sharp productivity growth and industrial transformation. Little has been done about the effects of the sequential privatization observed in China. Notable exceptions include the recent theoretical work by Song et al. (2011) and Wang et al. (2012), who both highlight and rationalize the high profitability of SOEs. ${ }^{10}$ Our papers focus on quantifying the export patterns of SOEs themselves and how they affect other types of exporters. Our estimation can be used to examine some of the specific predictions in these theoretical models.

The rest of this paper is organized as follows. Section 2 develops our conceptual model and estimation methods. Section 3 explains our data. Section 4 analyzes our estimation results. Section 5 concludes, with discussions on potential policy implications and future research.

\section{Conceptual Model and Estimation Method}

This section first develops a model to split a conventional IO table into sub-accounts that record domestic transactions between different firm types across sectors. It then describes how we use constrained optimization techniques along with various adding-up conditions to estimate those transactions. Readers

\footnotetext{
${ }^{8}$ As Bernard et al. (2007) described "engaging in international trade is an exceedingly rare activity: of the 5.5 million firms operating in the United States in 2000, just 4 percent were exporters. Among these exporting firms, the top 10 percent accounted for 96 percent of total U.S. exports.”

9 A notable exception is the report by the USITC (2010), who also uses the constrained optimization methodology to estimate the contribution of small and medium enterprise (SMEs) to US exports. The report finds that SMEs' total contribution to U.S. exports increased from less than $28 \%$ to $41 \%$ in 2007 , when the value of intermediates supplied by SMEs to exporting firms is taken into account.

${ }^{10}$ Song et al. (2011) further uses the unique feature of SOEs in China to explain several macro outcomes, such as huge saving and current account surplus.
} 
who are primarily interested in the estimation outcomes can skip this section and go to Section 3 directly.

\subsection{Conceptual Model}

Our conceptual model is built on the conventional IO table, which includes information on sales of intermediate goods and services by one industry to another in the domestic economy. By construction, summing up entries horizontally across each row and vertically across each column will both give the total gross output of an industry. The vertical summation is analogous to the cost approach of measuring a country's gross output, which decomposes gross output into different types of intermediate and primary factor inputs. The horizontal summation is analogous to the sales approach of measuring a country's gross output, which decomposes an industry's gross output into its various domestic usages and exports. To study the intra-national trade between different types of firms based on their ownership and size, we first split the non-competitive IO table with 42 industries from China's National Statistics Bureau (NBS hereafter) into 6 sub-accounts. ${ }^{11}$ The 6 sub-accounts are constructed based on 3 ownership types - SOEs, FIEs, and Others (i.e., non-FIE private), and 2 sizes - large and small-and-medium. Thus, there are altogether 252 groups (42 industries x 3 ownership types x 2 sizes). To estimate the volume of domestic transaction between each pair of firm groups, there will be 252 x 252 (including the within-group transactions between different firms) unknowns to estimate. See Fig. 1 for an illustration of the extended IO table.

In the IO table, $Z, Y, E, X$, and $M$ represent, respectively, intermediate inputs, domestic final demand, exports, total output, and imports. We use a two-alphabet superscript to denote one of the 6 firm groups. The first alphabet denotes ownership type (S, F, or O) while the second subscript denotes size (L or S). A combination of a size and an ownership type gives us a firm group, $g$. Specifically, $g$ can be $S L, S S, F L$, FS, OL, and OS, which represent Large SOE, Small SOE, Large FIE, Small FIE, Large Others, and Small Others, respectively. Subscripts $i$ and $j$ are for supplying and buying product categories (42 of them), which we will mostly refer to as sectors from now on.

Fig. 1 shows our extended IO table with 6 firm types. The last two rows report value added and the column sum of gross output, respectively. The last three columns are respectively domestic final use, exports, and total gross output, which is equal to the row sum by construction (i.e., the IO balance

\footnotetext{
${ }^{11}$ The non-competitive IO table assumes that imported and domestic products are not substitutable, in contrast to the standard IO table that assumes perfect substitutability between imported and domestic products. When competitive IO tables are used, only one set IO coefficients are needed. The underlying Leontief or linear production functions assumed in either approach have their obvious drawbacks, but we consider our approach, which permits different IO coefficients on imported and domestic inputs across sector-pairs, to be more suitable for the purpose of our study.
} 
condition). The remaining part of the matrix is a $6 \times 6$ blocks of square matrices, each of which is $42 \times 42$ in dimension. For example, $\mathrm{Z}^{\mathrm{SL}, \mathrm{SL}}$ in the first row (SL) and first column (SL) is a $42 \mathrm{x} 42$ matrix, with an element in row $i$ and column $j, z_{i j}^{S L, S L}$, representing output produced by LSOEs in sector $i$ used as intermediate inputs by other LSOEs in sector $j$. Moving horizontally across the first row, each matrix, $\mathrm{Z}^{\mathrm{SL}, \mathrm{g}}$, is a $42 \mathrm{x} 42$ matrix with an element $z_{i j}^{\mathrm{SL}, \mathrm{g}}$ in row $i$ and column $j$ representing output that is still produced by LSOEs in sector $i$ but is used as intermediate inputs by group-g firms (e.g., SS) in sector $j$. Similarly, when moving down vertically within a column, each entry is a $42 \mathrm{x} 42$ matrix, $\mathrm{Z}^{\mathrm{g} 1 \mathrm{~g} 2}$, with elements, $z_{i j}^{\mathrm{g} 1, \mathrm{~g} 2}$, being the output produced by firms in group g1 and sector $i$, and used as intermediate inputs by firms in group g2 and sector $j$.

Moving to the last three rows of the split IO table, the first 6 entries in row 7 (F) are 42x42 matrices, $Z^{\mathrm{F}, \mathrm{g} 2}$. The element in row $i$ and column $j$ of $Z^{F, g 2}, z_{i j}^{\mathrm{F}, \mathrm{g} 2}$, represents product $i$ imports that are used as intermediate inputs by group-g2 (e.g., SL) firms in sector $j$. The $7^{\text {th }}$ entry, $\mathrm{Y}^{\mathrm{F}}$, is a $42 \mathrm{x} 1$ vector, with element, $y_{i}^{F}$, being the total amount of product $i$ imports for final consumption. The last entry in row 7, $M$, is a $42 \times 1$ vector, with element $m_{i}$ representing total imports of product $i$. By definition, $m_{i}$ is the sum of first 7 entries in the same row.

Rows 8 and 9 in Fig. 1 show sectoral value added and gross output of the 6 different firm groups, respectively. For example, in the first column in Row $8, V^{\mathrm{SL}}$ is a $1 \mathrm{x} 42$ row vector that has element $i$ equal to the direct value added of LSOE in sector $i$ (cost of production factors). In the last row, $\left(\mathrm{X}^{\mathrm{SL}}\right)^{\mathrm{T}}$ is a $1 \times 42$ row vector with element $i$ being the gross output of LSOE in sector $i$. Superscript T represents the transpose operation. Other $\mathrm{X}$ and $\mathrm{V}$ matrices are defined similarly for different firm groups.

The direct IO coefficients in the expanded IO table can be expressed in matrix algebra as:

$$
\begin{gathered}
\mathrm{A}^{\mathrm{g} 1, \mathrm{~g} 2}=\left[a_{i j}^{g 1, g 2}\right]=\left[\frac{z_{i j}^{g 1, g 2}}{x_{j}^{g 2}}\right] \\
\text { and } \mathrm{A}^{\mathrm{F}, \mathrm{g} 2}=\left[a_{i j}^{F, g 2}\right]=\left[\frac{z_{i j}^{F, g 2}}{x_{j}^{g 2}}\right]
\end{gathered}
$$

where $i$ is the row subscript and $j$ is the column subscript. $\mathrm{A}^{\mathrm{g} 1, \mathrm{~g} 2}$ is a $42 \mathrm{x} 42$ block matrix, with each element being an IO coefficient representing the amount of output produced by firms in group g1 used as intermediate inputs in the production of one unit of output by group-g2 firms. More specifically, $x_{j}^{g 2}$ represents output by group-g2 firms in sector $j$, where g2 can be either LS, SS, LF, SF, OL, or OS, 
respectively. It is also the jth element in $\left(\mathrm{X}^{\mathrm{g} 2}\right)^{\mathrm{T}}$ in the last row of Fig. $1 . z_{i j}^{g 1, g 2}$ is the amount of sector $i$ output produced by group-g1 firms that are used by group-g2 firms in sector $j$. It is the element in row $i$ and column $j$ of $Z_{j}^{\mathrm{g} 1, \mathrm{~g} 2}$. Similarly, $\mathrm{A}^{\mathrm{F}, \mathrm{g} 2}$ is a $42 \times 42$ matrix, with each element being an IO coefficient measuring the amount of imported goods used as intermediate inputs by group-g2 firms to produce one unit of gross output. In other words, the element in row $\underline{i}$ and column $j$ of $\mathrm{Z}_{\mathrm{j}}^{\mathrm{F}, \mathrm{g} 2}$ in the $3^{\mathrm{rd}}$ row from the bottom of Fig. $1, z_{i j}^{F, g 2}$, is the amount of sector-i imports used by group-g2 firms in sector $j$.

We then obtain matrix A, with 294 (7x42) rows and 252 (6x42) columns, to represent all IO coefficients in the economy as follows:

$$
\mathrm{A}=\left[\begin{array}{c}
A^{d} \\
---- \\
A^{m}
\end{array}\right]
$$

where

$$
A^{d}=\left[\begin{array}{llllll}
A^{\mathrm{SL}, S L} & A^{\mathrm{SL}, S S} & \mathrm{~A}^{\mathrm{SL}, \mathrm{FL}} & \mathrm{A}^{\mathrm{SL}, \mathrm{FS}} & A^{\mathrm{SL}, \mathrm{OL}} & A^{\mathrm{SL}, \mathrm{OS}} \\
\mathrm{A}^{\mathrm{SS}, \mathrm{SL}} & \mathrm{A}^{\mathrm{SS}, \mathrm{SS}} & \mathrm{A}^{\mathrm{SS}, \mathrm{FL}} & \mathrm{A}^{\mathrm{SS}, \mathrm{FS}} & \mathrm{A}^{\mathrm{SS}, \mathrm{OL}} & \mathrm{A}^{\mathrm{SS}, \mathrm{OS}} \\
\mathrm{A}^{\mathrm{FL}, \mathrm{SL}} & \mathrm{A}^{\mathrm{FL}, \mathrm{SS}} & \mathrm{A}^{\mathrm{FL}, \mathrm{FL}} & \mathrm{A}^{\mathrm{FL}, \mathrm{FS}} & \mathrm{A}^{\mathrm{FL}, \mathrm{OL}} & \mathrm{A}^{\mathrm{FL}, \mathrm{OS}} \\
\mathrm{A}^{\mathrm{FS}, \mathrm{SL}} & \mathrm{A}^{\mathrm{FS}, \mathrm{SS}} & \mathrm{A}^{\mathrm{FS}, \mathrm{FL}} & \mathrm{A}^{\mathrm{FS}, \mathrm{FS}} & \mathrm{A}^{\mathrm{FS}, \mathrm{OL}} & \mathrm{A}^{\mathrm{FS}, \mathrm{OS}} \\
\mathrm{A}^{\mathrm{OL}, \mathrm{SL}} & \mathrm{A}^{\mathrm{OL}, \mathrm{SS}} & \mathrm{A}^{\mathrm{OL}, \mathrm{FL}} & \mathrm{A}^{\mathrm{OL}, \mathrm{FS}} & \mathrm{A}^{\mathrm{OL}, \mathrm{OL}} & \mathrm{A}^{\mathrm{OL}, \mathrm{OS}} \\
\mathrm{A}^{\mathrm{OS}, \mathrm{SL}} & \mathrm{A}^{\mathrm{OS}, \mathrm{SS}} & \mathrm{A}^{\mathrm{OS}, \mathrm{FL}} & \mathrm{A}^{\mathrm{OS}, \mathrm{FS}} & \mathrm{A}^{\mathrm{OS}, \mathrm{OL}} & \mathrm{A}^{\mathrm{OS}, \mathrm{OS}}
\end{array}\right]
$$

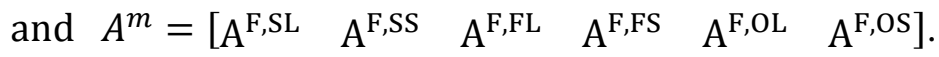

Thus, final demand for domestically produced goods can be expressed as

$$
X=A^{d} X+Y^{d}+E
$$

where $X=\left[\begin{array}{c}X^{S L} \\ X^{S S} \\ X^{F L} \\ X^{F S} \\ X^{O L} \\ X^{O S}\end{array}\right], Y^{d}=\left[\begin{array}{c}Y^{S L} \\ Y^{S S} \\ Y^{F L} \\ Y^{F S} \\ Y^{O L} \\ Y^{O S}\end{array}\right]$, and $E=\left[\begin{array}{c}E^{S L} \\ E^{S S} \\ E^{F L} \\ E^{F S} \\ E^{O L} \\ E^{O S}\end{array}\right]$

(i.e., the gross output, domestic final use, and export vectors). Rearranging eq. (1) gives 


$$
X=\left(I-A^{d}\right)^{-1} Y^{d}+\left(I-A^{d}\right)^{-1} E=B Y^{d}+B E
$$

where $\mathrm{B}$ is the well-known Leontief matrix:

$$
B=\left(\mathrm{I}-\mathrm{A}^{\mathrm{d}}\right)^{-1}=\left[\begin{array}{llllll}
\mathrm{B}^{\mathrm{SL}, \mathrm{SL}} & \mathrm{B}^{\mathrm{SL}, \mathrm{SS}} & \mathrm{B}^{\mathrm{SL}, \mathrm{FL}} & \mathrm{B}^{\mathrm{SL}, \mathrm{FS}} & \mathrm{B}^{\mathrm{SL}, \mathrm{OL}} & \mathrm{B}^{\mathrm{SL}, \mathrm{OS}} \\
\mathrm{B}^{\mathrm{SS}, \mathrm{SL}} & \mathrm{B}^{\mathrm{SS}, \mathrm{SS}} & \mathrm{B}^{\mathrm{SS}, \mathrm{FL}} & \mathrm{B}^{\mathrm{SS}, \mathrm{FS}} & \mathrm{B}^{\mathrm{SS}, \mathrm{OL}} & \mathrm{B}^{\mathrm{SS}, \mathrm{OS}} \\
\mathrm{B}^{\mathrm{FL}, \mathrm{SL}} & \mathrm{B}^{\mathrm{FL}, S S} & \mathrm{~B}^{\mathrm{FL}, \mathrm{FL}} & \mathrm{B}^{\mathrm{FL}, \mathrm{FS}} & \mathrm{B}^{\mathrm{FL}, \mathrm{OL}} & \mathrm{B}^{\mathrm{FL}, \mathrm{OS}} \\
\mathrm{B}^{\mathrm{FS}, \mathrm{SL}} & \mathrm{B}^{\mathrm{FS}, \mathrm{SS}} & \mathrm{B}^{\mathrm{FS}, \mathrm{FL}} & \mathrm{B}^{\mathrm{FS}, \mathrm{FS}} & \mathrm{B}^{\mathrm{FS}, \mathrm{OL}} & \mathrm{B}^{\mathrm{FS}, \mathrm{OS}} \\
\mathrm{B}^{\mathrm{OL}, \mathrm{SL}} & \mathrm{B}^{\mathrm{OL}, \mathrm{SS}} & \mathrm{B}^{\mathrm{OL}, \mathrm{FL}} & \mathrm{B}^{\mathrm{OL}, \mathrm{FS}} & \mathrm{B}^{\mathrm{OL}, \mathrm{OL}} & \mathrm{B}^{\mathrm{OL}, \mathrm{OS}} \\
\mathrm{B}^{\mathrm{OS}, \mathrm{SL}} & \mathrm{B}^{\mathrm{OS}, \mathrm{SS}} & \mathrm{B}^{\mathrm{OS}, \mathrm{FL}} & \mathrm{B}^{\mathrm{OS}, \mathrm{FS}} & \mathrm{B}^{\mathrm{OS}, \mathrm{OL}} & \mathrm{B}^{\mathrm{OS}, \mathrm{OS}}
\end{array}\right]
$$

where $\mathrm{B}^{\mathrm{g} 1, \mathrm{~g} 2}$ is a $42 \mathrm{x} 42$ block matrix, each element in which is the total requirement coefficient that gives the amount of required gross output by firm group $\mathrm{g} 1$ for one additional unit of domestic final demand or exports. The intuition behind the Leontief matrix is as follows: for each dollar of exports, the first round of value added is generated by the direct exporters. This is the direct domestic value added. To produce that value added, intermediate inputs have to be used, which in turn generate additional value added, and so on. Such a process of value-added generation continues iteratively and can be traced throughout the domestic input-output linkage across firm types and sectors in the economy. The total domestic value added induced by one dollar of exports is thus equal to the sum of direct and all rounds of indirect domestic value added generated.

Before getting to the domestic input-output linkage, let us briefly discuss the import identity, which we will use to trace the indirect linkage across industries (from final sales back to the value-added embodied in all upstream intermediate inputs) to distribute export value back to different sources of supply, including foreign suppliers. As imports can be absorbed as final goods and used as intermediate inputs, the import matrix, $\mathrm{M}$, can be expressed as

$$
M=A^{m} X+Y^{m}
$$

Substituting (2) into (3) yields

$$
M=A^{m} B Y^{d}+A^{m} B E+Y^{m}
$$

The first term on the right hand side of eq. (4), $A^{m} B Y^{d}$, represents imports used (both directly and indirectly) to produce final products for domestic use, $\mathrm{A}^{\mathrm{m}} \mathrm{BE}$ stands for imports used (both directly and indirectly) through the domestic input-output network to produce exports. It will be used below to estimate foreign value-added in exports. $\mathrm{Y}^{\mathrm{m}}$ represents the amount of imports that are consumed 
as final goods.

Let us define $A_{V}^{\mathrm{g} 1}=\left[\begin{array}{l}v_{j}^{\mathrm{g} 1} \\ \mathrm{x}_{\mathrm{j}}^{\mathrm{g} 1}\end{array}\right]$ as the value added vector (1 by 42) for firm group g1 where $v_{\mathrm{j}}^{\mathrm{g} 1}$ is the jth element of $V^{\mathrm{g} 1}$ in the second last row in Fig. 1; and $A_{V}=\left[\mathrm{A}_{V}^{\mathrm{SL}}, \mathrm{A}_{V}^{\mathrm{SS}}, \mathrm{A}_{V}^{\mathrm{FL}}, \mathrm{A}_{V}^{\mathrm{FS}}, \mathrm{A}_{V}^{\mathrm{OL}}, \mathrm{A}_{V}^{\mathrm{OS}}\right]$ as the $1 \mathrm{x} 252$ row vector of value added, covering all sectors and firm groups.

Because total gross output $(\mathrm{X})$ in any sector has to be equal to the sum of direct value-added $\mathrm{V}$, plus the cost of domestic intermediate inputs $\left(\mathrm{Z}^{\mathrm{g} 1, \mathrm{~g} 2}\right)$ from all firm types and imported inputs, $\left(\mathrm{Z}^{\mathrm{F}, \mathrm{g}}\right)$, the following accounting identity always holds :

$$
\mathrm{u}=A_{V}+\mathrm{uA} \mathrm{A}^{\mathrm{d}}+\vartheta \mathrm{A}^{\mathrm{m}}
$$

which means that each unit of output can be attributed to direct value added, domestic intermediate inputs, and imported intermediate inputs. u a 1x252 row vector and $\vartheta$ is a $1 \times 42$ row vector, respectively.

Taking $\mathrm{uA}^{\mathrm{d}}$ to the left hand side of eq. (5) and rearranging it yields

$$
\mathrm{u}=A_{V}\left(\mathrm{I}-\mathrm{A}^{\mathrm{d}}\right)^{-1}+\vartheta \mathrm{A}^{\mathrm{m}}\left(\mathrm{I}-\mathrm{A}^{\mathrm{d}}\right)^{-1}=A_{V} \mathrm{~B}+\vartheta \mathrm{A}^{\mathrm{m}} \mathrm{B}
$$

Post-multiplying both sides of eq. (6) by the diagonal matrix of exports, $\widehat{E}$, yields

$$
u \widehat{E}=A_{V} B \widehat{E}+\vartheta A^{m} B \widehat{E}
$$

Notice that $A_{V}=\mathrm{u} \hat{A}_{V}$, where $\hat{A}_{V}$ is the diagonal matrix of $A_{V}$ with the dimension of 252x 252 . Thus, eq. (7) can be further be rewritten as

$$
u \widehat{E}=u \widehat{A}_{V} B \widehat{E}+\vartheta A^{m} B \widehat{E}
$$

Eq. (8) states that the country's total gross export value, $u \widehat{E}$, a $1 \times 252$ row vector, can be decomposed into domestic value added in exports $\mathrm{u} \hat{A}_{V} \mathrm{BE}$ (either used directly for production of exported goods and services, or indirectly by firms that supply domestic inputs that are used eventually by exporters) and the value of imports embedded in exports $\vartheta \mathrm{A}^{\mathrm{m}} \mathrm{B} \widehat{\mathrm{E}}$, which includes imported intermediates used directly by exporters or embodied in other domestic intermediates finally used by them.

In eq. (8), the first term on the right hand side, $u \widehat{A}_{V} B \widehat{E}$, is the key to our quantification of domestic value added (DVA) in Chinese exports. Specifically, $\widehat{A}_{V} B \widehat{E}$ is a $252 \times 252$ square matrix, with each element representing the source (from which product category and firm type) and the channel (indirectly used in 
which product category and firm type) of domestic value added in exports. Depending on the research question, one can aggregate $\hat{A}_{\mathrm{V}} \mathrm{B} \widehat{\mathrm{E}}$ horizontally or vertically to estimate DVA in exports. If the goal is to decompose DVA in exports of the direct exporting sectors by firm type into its various sources of value added, regardless of which sector or firm-type the value added is originally created, we should sum up the elements of $\hat{A}_{\mathrm{V}} \mathrm{BE}$ vertically down a column (the backward-linkage approach). If the goal is to measure DVA based on their source of contribution by industry-firm-type, we should sum up the elements of $\hat{A}_{\mathrm{V}} \mathrm{B} \widehat{\mathrm{E}}$ horizontally along each row (the forward-linkage approach) ${ }^{12}$. In other words, we will first use the forward-linkage approach to examine how primary factors employed in a particular upstream sector-firm-type pair contributes value-added to every downstream sector-firm-type pair's exports. Then we will discuss the backward-linkage approach to examine how each downstream firm-type and sector's exports can be sourced back to each upstream sector-firm-type pair's value-added.

Since we need to deal with not only intermediate inputs supplied directly to the exporters, but also those through the domestic input-output network iteratively before reaching the direct exporting sectors and firm groups, we further decompose the Leontief matrix B to compute direct and indirect domestic value-added exports separately. Let us rewrite B as follows

$$
\begin{aligned}
B & =\left[\begin{array}{llllll}
\mathrm{B}^{\mathrm{SL}, \mathrm{SL}} & \mathrm{B}^{\mathrm{SL}, \mathrm{SS}} & \mathrm{B}^{\mathrm{SL}, \mathrm{FL}} & \mathrm{B}^{\mathrm{SL}, \mathrm{FS}} & \mathrm{B}^{\mathrm{SL}, \mathrm{OL}} & \mathrm{B}^{\mathrm{SL}, \mathrm{OS}} \\
\mathrm{B}^{\mathrm{SS}, \mathrm{SL}} & \mathrm{B}^{\mathrm{SS}, \mathrm{SS}} & \mathrm{B}^{\mathrm{SS}, \mathrm{FL}} & \mathrm{B}^{\mathrm{SS}, \mathrm{FS}} & \mathrm{B}^{\mathrm{SS}, \mathrm{OL}} & \mathrm{B}^{\mathrm{SS}, \mathrm{OS}} \\
\mathrm{B}^{\mathrm{FL}, \mathrm{SL}} & \mathrm{B}^{\mathrm{FL}, \mathrm{SS}} & \mathrm{B}^{\mathrm{FL}, \mathrm{FL}} & \mathrm{B}^{\mathrm{FL}, \mathrm{FS}} & \mathrm{B}^{\mathrm{FL}, \mathrm{OL}} & \mathrm{B}^{\mathrm{FL}, \mathrm{OS}} \\
\mathrm{B}^{\mathrm{FS}, \mathrm{SL}} & \mathrm{B}^{\mathrm{FS}, \mathrm{SS}} & \mathrm{B}^{\mathrm{FS}, \mathrm{FL}} & \mathrm{B}^{\mathrm{FS}, \mathrm{FS}} & \mathrm{B}^{\mathrm{FS}, \mathrm{OL}} & \mathrm{B}^{\mathrm{FS}, \mathrm{OS}} \\
\mathrm{B}^{\mathrm{OL}, \mathrm{SL}} & \mathrm{B}^{\mathrm{OL}, \mathrm{SS}} & \mathrm{B}^{\mathrm{OL}, \mathrm{FL}} & \mathrm{B}^{\mathrm{OL}, \mathrm{FS}} & \mathrm{B}^{\mathrm{OL}, \mathrm{OL}} & \mathrm{B}^{\mathrm{OL}, \mathrm{OS}} \\
\mathrm{B}^{\mathrm{OS}, \mathrm{SL}} & \mathrm{B}^{\mathrm{OS}, \mathrm{SS}} & \mathrm{B}^{\mathrm{OS}, \mathrm{FL}} & \mathrm{B}^{\mathrm{OS}, \mathrm{FS}} & \mathrm{B}^{\mathrm{OS}, \mathrm{OL}} & \mathrm{B}^{\mathrm{OS}, \mathrm{OS}}
\end{array}\right] \\
= & {\left[\begin{array}{llllll}
\mathrm{B}^{\mathrm{SL}, \mathrm{SL}}-\mathrm{I} & \mathrm{B}^{\mathrm{SL}, \mathrm{SS}} & \mathrm{B}^{\mathrm{SL}, \mathrm{FL}} & \mathrm{B}^{\mathrm{SL}, \mathrm{FS}} & \mathrm{B}^{\mathrm{SL}, \mathrm{OL}} & \mathrm{B}^{\mathrm{SL}, \mathrm{OS}} \\
\mathrm{B}^{\mathrm{SS}, \mathrm{SL}} & \mathrm{B}^{\mathrm{SS}, \mathrm{SS}}-\mathrm{I} & \mathrm{B}^{\mathrm{SS}, \mathrm{FL}} & \mathrm{B}^{\mathrm{SS}, \mathrm{FS}} & \mathrm{B}^{\mathrm{SS}, \mathrm{OL}} & \mathrm{B}^{\mathrm{SS}, \mathrm{OS}} \\
\mathrm{B}^{\mathrm{FL}, \mathrm{SL}} & \mathrm{B}^{\mathrm{FL}, \mathrm{SS}} & \mathrm{B}^{\mathrm{FL}, \mathrm{FL}}-\mathrm{I} & \mathrm{B}^{\mathrm{FL}, \mathrm{FS}} & \mathrm{B}^{\mathrm{FL}, \mathrm{OL}} & \mathrm{B}^{\mathrm{FL}, \mathrm{OS}} \\
\mathrm{B}^{\mathrm{FS}, \mathrm{SL}} & \mathrm{B}^{\mathrm{FS}, \mathrm{SS}} & \mathrm{B}^{\mathrm{FS}, \mathrm{FL}} & \mathrm{B}^{\mathrm{FS}, \mathrm{FS}}-\mathrm{I} & \mathrm{B}^{\mathrm{FS}, \mathrm{OL}} & \mathrm{B}^{\mathrm{FS}, \mathrm{OS}} \\
\mathrm{B}^{\mathrm{OL}, \mathrm{SL}} & \mathrm{B}^{\mathrm{OL}, \mathrm{SS}} & \mathrm{B}^{\mathrm{OL}, \mathrm{FL}} & \mathrm{B}^{\mathrm{OL}, \mathrm{FS}} & \mathrm{B}^{\mathrm{OL}, \mathrm{OL}}-\mathrm{I} & \mathrm{B}^{\mathrm{OL}, \mathrm{OS}} \\
\mathrm{B}^{\mathrm{OS}, \mathrm{SL}} & \mathrm{B}^{\mathrm{OS}, \mathrm{SS}} & \mathrm{B}^{\mathrm{OS}, \mathrm{FL}} & \mathrm{B}^{\mathrm{OS}, \mathrm{FS}} & \mathrm{B}^{\mathrm{OS}, \mathrm{OL}} & \mathrm{B}^{\mathrm{OS}, \mathrm{OS}}-\mathrm{I}
\end{array}\right] }
\end{aligned}
$$

\footnotetext{
12 See Wang, Wei and Zhu (2013) for a more detailed discussion on forward- and backward-linkage approaches to measure value-added exports.
} 


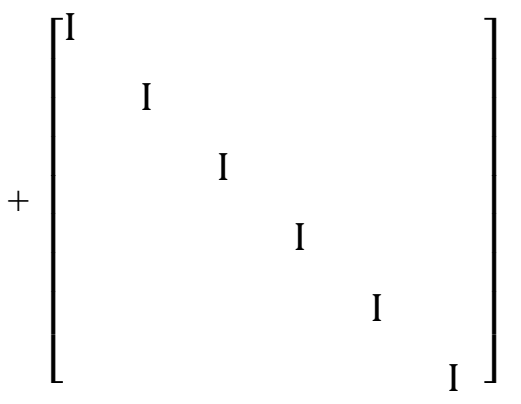

Then DVA in exports at the most disaggregated level can be decomposed as

$$
\operatorname{DVAX}=\widehat{\mathrm{A}}_{\mathrm{V}} \mathrm{B} \widehat{\mathrm{E}}=\widehat{\mathrm{A}}_{\mathrm{V}} \widehat{\mathrm{E}}+\widehat{\mathrm{A}}_{\mathrm{V}}(\mathrm{B}-\mathrm{I}) \widehat{\mathrm{E}}
$$

where $\mathrm{B}-\mathrm{I}=\left[\begin{array}{llllll}\mathrm{B}^{\mathrm{SL}, S L}-\mathrm{I} & \mathrm{B}^{\mathrm{SL}, \mathrm{SS}} & \mathrm{B}^{\mathrm{SL}, \mathrm{FL}} & \mathrm{B}^{\mathrm{SL}, \mathrm{FS}} & \mathrm{B}^{\mathrm{SL}, \mathrm{OL}} & \mathrm{B}^{\mathrm{SL}, \mathrm{OS}} \\ \mathrm{B}^{\mathrm{SS}, \mathrm{SL}} & \mathrm{B}^{\mathrm{SS}, \mathrm{SS}}-\mathrm{I} & \mathrm{B}^{\mathrm{SS}, \mathrm{FL}} & \mathrm{B}^{\mathrm{SS}, \mathrm{FS}} & \mathrm{B}^{\mathrm{SS}, \mathrm{OL}} & \mathrm{B}^{\mathrm{SS}, \mathrm{OS}} \\ \mathrm{B}^{\mathrm{FL}, \mathrm{SL}} & \mathrm{B}^{\mathrm{FL}, \mathrm{SS}} & \mathrm{B}^{\mathrm{FL}, \mathrm{FL}}-\mathrm{I} & \mathrm{B}^{\mathrm{FL}, \mathrm{FS}} & \mathrm{B}^{\mathrm{FL}, \mathrm{OL}} & \mathrm{B}^{\mathrm{FL}, \mathrm{OS}} \\ \mathrm{B}^{\mathrm{FS}, \mathrm{SL}} & \mathrm{B}^{\mathrm{FS}, \mathrm{SS}} & \mathrm{B}^{\mathrm{FS}, \mathrm{FL}} & \mathrm{B}^{\mathrm{FS}, \mathrm{FS}}-\mathrm{I}^{\mathrm{FS}, \mathrm{OL}} & \mathrm{B}^{\mathrm{FS}, \mathrm{OS}} \\ \mathrm{B}^{\mathrm{OL}, \mathrm{SL}} & \mathrm{B}^{\mathrm{OL}, \mathrm{SS}} & \mathrm{B}^{\mathrm{OL}, \mathrm{FL}} & \mathrm{B}^{\mathrm{OL}, \mathrm{FS}} & \mathrm{B}^{\mathrm{OL}, \mathrm{OL}}-\mathrm{I} & \mathrm{B}^{\mathrm{OL}, \mathrm{OS}} \\ \mathrm{B}^{\mathrm{OS}, \mathrm{SL}} & \mathrm{B}^{\mathrm{OS}, \mathrm{SS}} & \mathrm{B}^{\mathrm{OS}, \mathrm{FL}} & \mathrm{B}^{\mathrm{OS}, \mathrm{FS}} & \mathrm{B}^{\mathrm{OS}, \mathrm{OL}} & \mathrm{B}^{\mathrm{OS}, \mathrm{OS}}-I_{I}\end{array}\right]$

Notice that DVAX is a 252x252 square matrix with two separate terms: the first term on the right hand side of eq. (9), $\widehat{A}_{V} \widehat{E}$, is direct DVA in exports, while the second term, $\widehat{A}_{V}(B-I) \widehat{E}$, is indirect DVA in exports. We can further decompose $\widehat{A}_{V}(B-I) \widehat{E}$ into indirect exports via other firms within the same firm group (e.g. SOEs exporting via SOEs) or via other firm groups (e.g., SOEs exporting via FIEs). The same-group indirect exports can be derived from the multiples involving only the diagonal of the block matrix inside the square brackets. The between-group indirect exports can be derived from the multiples involving only the off-diagonal part of the block matrix inside the square brackets.

To implement the forward-linkage (supply) approach so that we can trace the final use of VA created by primary factors employed in a particular sector-firm-type, we post-multiply both sides of eq. (9) by a 252x1 unit column vector, $\mu$. This operation essentially sums up each sector-firm-type's VA horizontally to obtain a measure of DVA in exports at the sector-firm-type level, regardless of which downstream sector-firm-type the VA are embedded. Formally, the forward-linkage based DVA in exports is

$$
\operatorname{DVAX}_{\mathrm{fw}}=\operatorname{DVAX} \mu=\widehat{A}_{V} \widehat{E} \mu+\widehat{A}_{V}(B-I) \widehat{E} \mu \text {, }
$$

where DVAX $\mathrm{fw}_{\mathrm{fw}}$ is a $252 \mathrm{x} 1$ column vector. $\hat{A}_{\mathrm{V}} \widehat{\mathrm{E}} \mu$ and $\hat{A}_{V}(B-I) \hat{E} \mu$ on the right hand side are direct and indirect value-added exports for each firm type at the sector level, respectively. Direct DVAX represents DVA that comes from the same sector-firm-group of the exporters. Indirect DVAX is the same 
sector-firm-group's DVA embodied in intermediate inputs supplied to other sectors and firms groups that eventually export.

Let us abstract from the sector dimension and focus on different firm groups for the moment. Eq. (10) can be further decomposed along the firm-type dimension. The first row in $\hat{A}_{V} \hat{E} \mu$ represents the direct VAX from large SOEs (SL). The first row of the second term, $\hat{A}_{V}(B-I) \hat{E} \mu$, is the sum of 6 multiples as follows:

$$
\begin{aligned}
& \hat{A}_{V}^{\mathrm{SL}}\left(\mathrm{B}^{\mathrm{SL}, \mathrm{SL}}-\mathrm{I}\right) \widehat{\mathrm{E}}^{\mathrm{SL}} \tilde{\mu}+\hat{A}_{V}^{\mathrm{SL}} \mathrm{B}^{\mathrm{SL}, \mathrm{SS}} \widehat{\mathrm{E}}^{\mathrm{SS}} \tilde{\mu}+\hat{A}_{V}^{\mathrm{SL}} \mathrm{B}^{\mathrm{SL}, \mathrm{FL}} \widehat{\mathrm{E}}^{\mathrm{FL}} \tilde{\mu} \\
& +\hat{A}_{V}^{\mathrm{SL}} \mathrm{B}^{\mathrm{SL}, \mathrm{FS}} \widehat{\mathrm{E}}^{\mathrm{FS}} \tilde{\mu}+\hat{A}_{V}^{\mathrm{SL}} \mathrm{B}^{\mathrm{SL}, \mathrm{OL}} \widehat{\mathrm{E}}^{\mathrm{OL}} \tilde{\mu}+\hat{A}_{V}^{\mathrm{SL}} \mathrm{B}^{\mathrm{SL}, \mathrm{OS}} \widehat{\mathrm{E}}^{\mathrm{OS}} \tilde{\mu},
\end{aligned}
$$

where $\tilde{\mu}$ is a $42 \times 1$ column vector. $\hat{A}_{V}^{\mathrm{SL}}\left(\mathrm{B}^{\mathrm{SL}, S L}-\mathrm{I}\right) \widehat{\mathrm{E}}^{\mathrm{SL}} \tilde{\mu}$ is indirect DVAX via large SOE firms, $\hat{A}_{V}^{\mathrm{SL}} \mathrm{B}^{\mathrm{SL}, \mathrm{SS}} \widehat{\mathrm{E}}^{\mathrm{SS}} \tilde{\mu}, \hat{A}_{V}^{\mathrm{SL}} \mathrm{B}^{\mathrm{SL}, \mathrm{FL}} \widehat{\mathrm{E}}^{\mathrm{FL}} \tilde{\mu}, \hat{A}_{V}^{\mathrm{SL}} \mathrm{B}^{\mathrm{SL}, \mathrm{FS}} \widehat{\mathrm{E}}^{\mathrm{FS}} \tilde{\mu}, \hat{A}_{V}^{\mathrm{SL}} \mathrm{B}^{\mathrm{SL}, \mathrm{OL}} \widehat{\mathrm{E}}^{\mathrm{OL}} \tilde{\mu}$, and $\hat{A}_{V}^{\mathrm{SL}} \mathrm{B}^{\mathrm{SL}, \mathrm{OS}} \widehat{\mathrm{E}}^{\mathrm{OS}} \tilde{\mu}$ represent LSOEs indirect VAX via SSOEs, LFIE, SFIE, LP, and SME's exports, respectively. Other rows in eq. (10) can be interpreted similarly for other firm types. Eq. (10) thus provides detailed information about the volume of direct and indirect DVAX, as well as through what types of firms that indirect exporting takes place. If we consider the 42 sectors within each firm-group-sector-pair, we can analyze these different components of VAX by sector. The estimates of direct and indirect VAX by 6 firm groups and 42 sectors are reported in Table A4.1-4.6 in the appendix.

To implement the backward-linkage (user) approach that decomposes each firm type's exports into their original value-added source by sector and firm-type, we pre-multiply both sides of eq. (9) by the 1x252 unit row vector $u$. This operation essentially sums up each sector-firm-type's VA vertically to obtain a measure of DVA at the sector-firm-type level. Formally, the backward-linkage based DVA in exports is

$$
\operatorname{DVAX}_{\mathrm{bw}}=u D V A X=u \widehat{A}_{V} \widehat{E}+u \widehat{A}_{V}(B-I) \widehat{E}
$$

By replacing $\mathrm{u} \hat{A}_{V} \mathrm{BE}$ in eq. (8) by eq. (12), we can completely decompose China's gross exports according to its various value-added sources as follows:

$$
u \widehat{E}=u \widehat{A}_{V} \widehat{E}+u \widehat{A}_{V}(B-I) \widehat{E}+\vartheta A^{m} B \widehat{E}
$$

Notice that all terms in eq. (13) are 1x252 row vectors.

Similar to our analysis of the forward-linkage based approach, let us abstract from the sector dimension and ignore value added from foreign sources (i.e., the $\vartheta \mathrm{A}^{\mathrm{m}} \mathrm{B} \widehat{\mathrm{E}}$ term) for the moment, so that we can 
focus on different firm groups. The first column of the first term, $u \widehat{A}_{V} \widehat{E}$, represents the direct value added exports by large SOEs (SL) in all 42 sectors. Notice the direct value-added exports based on the forward-linkage and backward-linkage approaches are identical (i.e. $\left(u \hat{A}_{V} \hat{E}\right)^{\mathrm{T}}$ in eq. (13) $=\hat{A}_{V} \hat{E} \mu$ in eq. (11)).

However, the indirect value-added exports measures can be very different for each firm group-sector pair. The two measures are only equal to each other at the country level (see WWZ, 2013 for details). In the second term, $u \hat{A}_{V}(B-I) \hat{E}$, the first column is the sum of 6 multiples as follows:

$$
\begin{aligned}
& \tilde{u} \widehat{A}_{V}^{S L}\left(B^{S L, S L}-I\right) \widehat{E}^{S L}+\tilde{u} \widehat{A}_{V}^{S S} B^{S S, S L} \widehat{E}^{S L}+\tilde{u} \widehat{A}_{V}^{F L} B^{F L, S L} \widehat{E}^{S L} \\
& +\tilde{u} \widehat{A}_{V}^{F S} B^{F S, S L} \widehat{E}^{S L}+\tilde{u} \widehat{A}_{V}^{S L} B^{O L, S L} \widehat{E}^{S L}+\tilde{u} B^{O S, S L} \widehat{E}^{S L}
\end{aligned}
$$

Where $\tilde{u}$ is a $1 \times 42$ row vector. $\tilde{u} \widehat{A}_{V}^{S L}\left(B^{S L, S L}-I\right) \widehat{E}^{S L}$ is LSOEs' indirect VAX via large LSOEs;

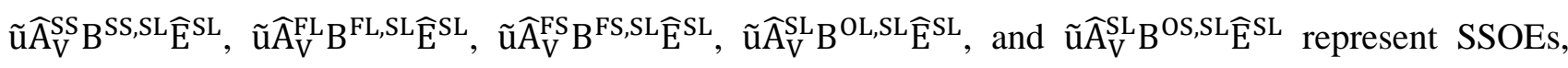
LFIE, SFIE, LP, and SME's value-added embodied in LSOE's gross exports, or these firm groups' indirect value-added exports via LSOE, respectively. Other columns of $u \hat{A}_{V}(B-I) \hat{E}$ in eq. (13) can be interpreted similarly for other firm groups. Therefore, eq. (14) thus provides detailed information about the value-added sources in exports produced by each firm group. If we consider the 42 sectors within each firm-group-pair, we can analyze the value-added composition for each firm group by sector. The full decomposition of each firm type's exports by value-added sourced from the 6 firm groups and 42 sectors are reported in Table A7 in the appendix.

\subsection{Estimation Method}

Eqs. (9)-(14) allow us to study the indirect value added by firm type at the aggregate and sector levels, decompose each firm group's sectoral exports into its various value-added sources, as well as shed light on the effects of exports on the distribution of operating surplus (an empirical measure of firm profit) across sectors and firm types. However, since statistical agencies in most countries normally provide only a conventional IO matrix, A, and not the disaggregated block matrices by firm groups, such as $\mathrm{A}^{\mathrm{g} 1, \mathrm{~g} 2}$ or $A^{F, g 2}$, we need to develop a method to construct those subaccounts from the original IO tables using information available from official statistics. IO tables already include data on industry-level total output, value added, imports, and exports as well aggregate inter-industry transactions. To estimate our extended model with 6 sub-accounts, we need to complement these aggregate data with firm-level data, which are from the 2008 National Bureau of Statistics of China (NBS hereafter) economic census. See Section 3 for 
details. $^{13}$

The following data are observable from a conventional IO table at the broad sector level (42 groups of products) for 2007 and 2010:

$x_{i}$ : gross output of sector $i$;

$z_{i j}^{D}$ : domestic goods $i$ used as intermediate inputs in sector $j$;

$z_{i j}^{F}$ : imported goods $i$ used as intermediate inputs in sector $j$;

$v_{j}$ : value added in sector $j$;

$e_{i}$ : total exports of sector $i$ goods;

$m_{i}$ : total imports of sector $i$ goods;

$y_{i}^{D}$ : total domestic final demand for sector $i$ goods (excluding exports);

$y_{i}^{F}$ : total final demand for imported goods $i$.

Using these data from the IO table as controls (constants) in the quadratic programming model, we make sure that the balance conditions in an official IO table are always satisfied. In other words, we can always aggregate values from our extended IO table with separate sub-accounts for firm groups back to the values in the original IO table.

We need to estimate the values of $\left[\mathrm{z}_{\mathrm{ij}}^{\mathrm{g} 1, \mathrm{~g} 2}\right]$ for each g1 and g2, where g1 and g2 belong to one of the six firm types, namely, SL, SS, FL, FS, OL, and OS. Similarly, we estimate $\left[\mathrm{z}_{\mathrm{ij}}^{\mathrm{F}, \mathrm{g}}\right]$ for one of the six firm types, indexed by g at the sector-pair level, indexed by (i, j). We also need to estimate sector-level domestic final demand by firm group, $\left[\mathrm{y}_{\mathrm{j}}^{\mathrm{g}}\right]$, which are not available from the official IO table but can be constructed using firm-level census data from the NBS and detailed trade statistics from China Custom Administration. We cast the estimation as a constrained optimization problem. Initial values are selected relying on proportionality assumptions (e.g., share of market demand in total output in each sector and firm group, which will be discussed next) and micro data from Chinese official sources. These initial values do not necessarily satisfy all economic and statistical restrictions on the split IO table.

Using the notations previously defined, the quadratic programming model is specified by the objective function in eq. (15) below, subject to the six constraints specified in eqs. (16) through (21) below. The initial values for the same variables in eq. (15) are denoted with an additional zero. Variables without a zero (the z's, and $y$ 's ) are unknowns that are to be solved by minimization. Symbols with a zero in eqs. (16) through (21) represent parameters in the model and are kept constant throughout the optimization

\footnotetext{
${ }^{13}$ One may prefer to call our optimization exercise a "calibration", especially since our exercise does not provide standard errors to gauge the precision of our estimates. We are open to this alternative interpretation, but would like to emphasize that in research in progress, we are extending our current optimization program with a Monte-Carlo-type first stage, which will provide standard errors for our estimates.
} 
process.

Specifically, the minimization program is

$$
\begin{aligned}
\operatorname{Min} S & =\sum_{g 1=S L}^{O S} \sum_{g 2=S L}^{O S}\left\{\sum_{i=1}^{K} \sum_{j=1}^{K} \frac{\left(z_{i j}^{g 1, g 2}-z 0_{i j}^{g 1, g 2}\right)^{2}}{z 0_{i j}^{g, f}}\right\} \\
& +\sum_{g=S L}^{O S}\left\{\sum_{i=1}^{K} \sum_{j=1}^{K} \frac{\left(z_{i j}^{F, g}-z 0_{i j}^{F, g}\right)^{2}}{z 0_{i j}^{F, g}}\right\}+\sum_{g=S L}^{O S}\left\{\sum_{j=1}^{K} \frac{\left(y_{j}^{g}-y 0_{j}^{g}\right)^{2}}{y 0_{j}^{g}}\right\}
\end{aligned}
$$

s.t.

$$
\begin{aligned}
& \sum_{g 2=S L}^{O S} \sum_{j=1}^{K}\left(z_{i j}^{g 1, g 2}\right)+y_{i}^{g 1}+e 0_{i}^{g 1}=x 0_{i}^{g 1} \\
& \sum_{g 1=S L}^{O S} \sum_{i=1}^{K}\left(z_{i j}^{g 1, g 2}\right)+v 0_{i}^{g 2}=x 0_{i}^{g 2} \\
& \sum_{g 1=S L}^{O S} \sum_{g 2=S L}^{O S} z_{i j}^{g 1, g 2}=z 0_{i j}^{D} \\
& \sum_{g=S L}^{O S} z_{i j}^{F, g}=z 0_{i j}^{F} \\
& \sum_{g=S L}^{O S} y_{i}^{g}=y 0_{i}^{D} \\
& \sum_{g=S L}^{O S} \sum_{j=1}^{K} z_{i j}^{F, g}+y 0_{i}^{F}=m 0_{i}
\end{aligned}
$$

And non-negativity constraints

$$
z_{i j}^{g 1, g 2}, \quad z_{i j}^{F, g}, \quad y_{i}^{g} \geq 0 .
$$

All constraints need to be satisfied for all $i$ (42 of them) and $j$ (42 of them), $g$ (6 of them), $g 1$ (6 of them), and $g 2$ (6 of them). These seven sets of constraints have straightforward economic interpretations. Eq. (16) is a set of supply-and-use balancing (row sum) constraints for the extended IO table. It states that total gross output by each type of firm in sector $i$, must equal the sum of their use of intermediate inputs, their exports, and their delivery to final domestic users in that sector. Eq. (17) is the set of production and cost balancing (column sum) constraints. It defines the value of gross output by each type of firm in sector $j$ as the sum of intermediate inputs and primary factors used in the production process. Eqs. (18) to (21) are a set of adding-up constraints to ensure that the solutions from the model sum to the statistics (i.e., domestic final demand, imports, and inter-sector transactions) in the official IO table at the sector and sector-pair levels.

\section{Data and Empirical Results}

\subsection{Data Sources and Model Variable Initialization}

The model parameters and initial values of the model variables are derived by combining industry-level 
data from the 42-sector "non-competitive” IO tables, for 2007 and 2010, respectively, along with firm census data for 2008. These data sets are obtained from China's National Bureau of Statistics (NBS). Notice that all evolution in value added by firm type reported below arise from the changes in the IO table coefficients, not from the census data as we only have access to one year of data. The economic census data cover over 5 million enterprises in China, including all state-owned and private enterprises spanning all manufacturing and non-manufacturing industries. Balance sheet information, such as registration ownership type, equity share by ownership, output, value added, four-digit industry code (about 900 categories,), exports, employment, original value of fixed asset, and intermediate inputs. The ownership type of a firm in our analysis is defined based on the registration type and equity share by ownership. Specifically, a firm is considered state-owned (foreign-invested) if it is registered as a state (foreign) company or has more than (and equal to) 50\% equity owned by state (foreign) investors.

There are 42 domestic and 42 imported product groups in the original "non-competitive" IO table. Each product group is further split into six sub-groups by ownership type and size: large SOEs (LSOE), small and medium SOEs (SSOE), large FIEs (LFIE), small and medium FIEs (SFIE) large private enterprises (LP), small and medium private enterprises (SME). Firm size category (large and small-and-medium) is determined by firm employment and sales, with thresholds specified by the NBS. The classification criteria vary across industries, and are listed in Table A1 in the appendix.

The decision of putting firms into 6 groups is supported by the underlying firm distribution of export intensity and value added to sales ratios reported in the NBS micro data. Fig. 2 illustrates that firm average export intensity differs significantly across ownership types, not so much along the firm size dimension. In particular, FIEs are a lot more export-oriented than non-FIE firms. Fig. 3 illustrates that FIEs also appear to have higher value added to output ratios (VAY) than non-FIE firms. Within non-FIE firms, large firms tend to have higher VAY. Within FIEs, there is little difference in these key variables between Hong Kong, Macau, and Taiwan (HKMT) firms and non-Chinese FIEs. Based on these findings, we separate firms based on 3 ownership types and 2 sizes, and group HKMT firms with other FIEs.

After assigning firms from the census to different groups, total sales/receipts at the group level are used to allocate gross output of each sector to each ownership-size type, while groups' annual payroll are used to split labor and non-labor components of the value added within the group. We can also assign exports (but not imports) into firm types in almost all industries using the firm census data. ${ }^{14}$ Detailed import data, obtained from the statistical department of China Customs Administration, are disaggregated by firm ownership type within each 8-digit HS level. UN BEC code is used to separate intermediates from

14 Export data are not available for most service sectors. 
final goods in imports at the 6 digit-HS level, which are then aggregated up to 42 product categories in the Chinese IO table. These data are used as import-related constraints and to set initial values for our minimization program.

All initial values $x 0_{j}^{g}$ and $v 0_{j}^{g}$ in the model, as well as an industry's total intermediate inputs were set based on official statistics. These values constrain the model solutions to a convex set. To initialize all $z 0_{i j}$ 's, we need to allocate each industry's total intermediate inputs, both domestic and imported, into different product groups by firm type. To this end, we first use the NBS firm census and the original IO table to compute for each firm type (6 of them), the sectoral (42 sectors) output $x 0_{j}^{g}$ and value added $v 0_{j}^{g}$. Then we compute total intermediate inputs $\left(x 0_{j}^{g}-v 0_{j}^{g}\right)$ for each sector and firm type, and compute the share of intermediate inputs of each firm type in sector $j$. Using these shares, we distribute the numbers $z 0_{i j}^{D}$ and $z 0_{i j}^{F}$ from the original IO table into 6 different firm types, e.g., $z 0_{i j}^{g 1, g 2}$. Table A5-6 in the appendix shows these shares by firm type in all 42 sectors. The specific procedures to set the initial values for our minimization program are described below.

1. Setting the initial value for $z 0_{i j}^{F, g}$ (the IO coefficients for imports for group g) involves two steps. For sectors that have zero intermediate imports in the trade statistics, but have positive values in the IO table, we simply use the shares of each firm type in the sector's total intermediate inputs and set the initial value for $z 0_{i j}^{F, g}$ as:

$z 0_{i j}^{F, g}=\frac{x 0_{j}^{g}-v 0_{j}^{g}}{\sum g, j\left(x 0_{j}^{g}-v 0_{j}^{g}\right)} z 0_{i j}^{F}, \quad(\mathrm{~g}=\mathrm{SL}, \mathrm{SS}, \mathrm{FL}, \mathrm{FS}, \mathrm{OL}, \mathrm{OS})$

On the other hand, for sectors that have positive imported intermediate inputs in the trade statistics, we first compute each firm group's share in the sector's imported inputs based on customs statistics, as shown in Table A6.2, to allocate imported inputs into SOEs, FIEs, and others. Using the adjusted $z 0_{i j}^{F}$ and eq. (23), we further allocate the imported inputs belonging to each ownership type to large and small firms within the same ownership type, respectively.

2. To set the initial value for $z 0_{i j}^{g 1, g 2}$ (the volume of domestic intermediates supplied by group g1 in sector $i$ to group g2 in sector $j$ ), we first assume that the share of intermediate inputs produced by g1 in sector $i$ equals the share of g1's gross output in sector $i$. Then on the receiving side, we assume that g2's share of intermediate input absorption in sector $j$ equals their share of intermediate inputs in total intermediate inputs demanded by the same sector. All these information are available in the firm census data. Based on these two assumptions, we split the original $z 0_{i j}^{D}$ based on the following 
formula:

$$
z 0_{i j}^{g 1, g 2}=\frac{x 0_{i}^{g 1}}{x 0_{i}} \frac{\left(x 0_{j}^{g 2}-v 0_{j}^{g 2}\right)}{\left(x 0_{j}-v 0_{j}\right)} z 0_{i j}^{D}, \quad(\mathrm{~g} 1, \mathrm{~g} 2=\mathrm{SL}, \mathrm{SS}, \mathrm{FL}, \mathrm{FS}, \mathrm{OL}, \mathrm{OS})
$$

3. To set the initial value for $y 0_{i}^{g}$, total domestic demand for goods and services supplied by firm group $g$ in sector $i$ (i.e., the sum of private consumption, government spending, fixed capital investment, and inventory changes), we use the following formula:

$$
y 0_{i}^{g}=x 0_{i}^{g}-\frac{x 0_{i}^{g}}{x 0_{i}} \sum_{j=1}^{N} z 0_{i j}^{D}-e 0_{i}^{g}
$$

Notice that we implicitly assume that the supply of intermediate products/inputs for domestic use from each firm type in a sector is proportional to their gross output in that sector. To make the model fully initialized and operational, we also need the relative shares of different firm types in the country's total exports and imports for each of the 42 sectors. Such information is readily available in the disaggregated trade statistics from China’s Customs.

\section{Estimating Indirect Contribution to Value-added Exports by Firm Size and Ownership Type}

\subsection{Main Results}

\subsubsection{Relative Importance in the Aggregate Economy}

Based on the estimates of the model described in Sections 2 and 3, we portray the domestic segment of GVC in China. Table 1 shows that SOEs account for $19 \%$ and $9 \%$ of value added and employment of China in 2008, respectively. The relatively small shares of SOEs are partly due to years of economic reforms led by the Chinese authorities to privatize and let go SOEs, especially the small ones in downstream sectors. SOEs' contributions to gross exports and value-added exports (VAX) in 2007 are 12\% and 21\%, respectively. The large difference between SOE's contributions to value added and gross exports suggests that SOEs have a higher share of indirect exports through other firms, compared to other firm ownership types. Notice that while SOEs' gross export share declined significantly from $12 \%$ in 2008 to $9 \%$ in 2010, their share in value added exports actually increased. We will focus on analyzing these opposite trends in greater detail below.

(Insert Table 1 here) 
Table 1 also shows that SMEs are numerous and employ the majority of workers in China. They account for 55\% and $79 \%$ of China's value added and employment in 2008, respectively. In terms of gross exports, their contribution is much smaller - only 28\%. This low share of exports is consistent with the conventional view that most small firms do not export because of the potentially high fixed export costs. In terms of value added exports, they account for $42 \%$. The much larger contribution to VAX implies that SMEs have a higher share of indirect exports, either through other SMEs or other types of firms. In terms of the aggregate gross exports and VAX, SOEs and SMEs look similar, but both the share of gross and value added exports by SMEs decreased from 2007 to 2010. We will reveal key underlying differences in terms of their distributions across industries and the channels through which they achieve a high value added to gross export ratio below.

As expected, FIEs are much more export-oriented. They are small in number, similar to SOEs, but account for close to half of Chinese gross exports. Their share in total value added exports is much smaller (only 27\%), consistent with the literature that finds low domestic value added in Chinese exports, particularly in processing exports (Koopman, Wang, and Wei, 2012; Kee and Tang, 2013). To the extent that most of the processing firms are FIEs, which include firms owned by investors from Hong Kong, Macau, and Taiwan (HKMT), the results are not surprising. Processing firms import a large fraction of intermediate inputs and are responsible for the final stage of production, by taking advantage of the low labor costs in China.

\subsubsection{The Domestic Segment of GVCs (VAX based on the Forward-linkage Approach)}

Next, we use our split IO tables to decompose VAX by firm type into direct and indirect VAX, based on both the forward- and backward-linkage approaches, as described in Section 2. We will first report results based on the forward-linkage approach.

For indirect VAX, we further measure the paths through which a firm type export indirectly. Table 2 presents these results, along with the volume of gross exports by firm type. Before turning to the details of indirect VAX, it is worth highlighting that for the 4 firm groups considered here, both SOE and SME have the VAXR exceeding 1. Specifically, Panel A shows that the VAXR of SOEs and SMEs are 1.17 and 1.02 in 2007, respectively. As a comparison, the VAXR of FIEs and LPs are 0.36 and 0.70, respectively. The finding of SOEs' VAXR larger than unity confirms the results in Table 1 that SOEs' contribution to Chinese exports is much larger if measured in value added terms than in gross terms. Moreover, these findings contrast sharply with the evidence for developed countries, such as the United States, where large firms' share in gross exports is usually higher than that in value-added exports (i.e., the 
VAXR is smaller than 1). In summary, the low VAX ratio of Chinese aggregate exports, as reported in the literature, hides substantial heterogeneity in VAX across firm ownership types and sizes.

Panel B of Table 2 shows the same set of estimates using 2010 IO table. As reported, all but FIEs experienced an increase in VAX. The increase was particularly sharp for SOEs and SMEs. SOEs' VAXR increased by about $47 \%$ while that of SMEs increased by about $27 \%$. The significant increase in the VAXR of SOEs lends some support to the anecdote that the state sector has advanced their prominence in the Chinese economy in recent years, especially after the global financial crisis in 2008 when the Chinese central government implemented policies to stimulate the economy.

(Insert Table 2 here)

The higher-than-unity VAXR of both SOEs and SMEs imply that many non-exporters from these two groups produce intermediate inputs and services that are embedded in Chinese exports. Table 2 reports the value of indirect exports. We find the following pecking order - SOEs have the highest share of indirect exports in VAX, followed by LPs and SMEs, with FIEs having the lowest share. Specifically, in 2007, about $80 \%$ of exports from SOEs are indirect (the numbers increased slightly in 2010). In other words, $80 \%$ of SOEs' exports are values embedded in inputs used by firms that eventually export. For LPs and SMEs, the indirect export shares are about $72 \%$ and 63\%, respectively. The indirect export share of SMEs increased significantly by 10 percentage points from 2007 to 2010, consistent with the hypothesis that small exporters could be financially constrained after the global finance crisis and less likely to engage in direct exporting. Once again, FIEs are very different from domestic firms and have a much lower share of indirect exports (about 46\% in 2007, which decreased to 43\% in 2010). Given the prevalence of FIEs in processing trade and the prevalence of intra-firm trade associated with vertical FDI, the low indirect export ratio is not surprising.

By splitting the IO table along the size and ownership type dimensions, we can also estimate the amount of indirect exports through different types of firms. As reported in Table 2, most of SOEs' indirect exports are through non-SOEs. In particular, in 2007, FIEs account for over 40\% (35/80) of SOEs' indirect exports, which increased to over 55\% in 2010. On the other hand, SMEs account for $25 \%$ of SOEs' indirect exports in 2007, which declined to about 20\% in 2010. Both LPs and SMEs also have high shares of indirect exports, but are both lower than that of SOEs. FIEs also play a more significant role in helping LPs to export indirectly, compared to SMEs. The role of SMEs in helping other firms export decreased from 2007 to 2010. For instance, when the SMEs' indirect export share increased from 2007 to 2010, the role of other SMEs in facilitating their exports declined, with FIEs taking up most of 
the increase. In summary, both SOEs and LPs have higher than average indirect export shares, with the former having a much higher VAX ratio. SMEs' participation in exporting, both direct and indirect, declined, while SOEs' indirect exports increased, consistent with an increasing VAX ratio as documented earlier.

How about the cross-industry pattern of indirect exports? Answering this question can shed light on the reasons for the similarity in the VAX ratio between SOEs and SMEs. Table 3 exhibits substantial heterogeneity in indirect export shares (in total value added exports) across 14 broad industries. "Upstream" industries, such as energy and mining; metal and non-metallic mineral extraction; electricity, gas and water supply; as well as financial sector all have very high indirect export shares (over 90\%). Tables A4.1-A4.6 in the appendix shows these numbers for 40 disaggregated industries and 6 groups of firms, revealing similar patterns. One reason for their high indirect export shares is that the sectors with high indirect export share tend to be non-tradable, either by nature or restricted by the authorities. They tend to export indirectly by providing essential intermediate inputs and services to downstream exporters. Thus, focusing only on gross exports in analyzing firms' export participation can substantially underestimate their actual participation in GVC and thus the impact of trade liberalization on the economy.

\section{(Insert Table 3 here)}

In addition to the cross-industry variation, within a sector we also see a non-negligible variation in the indirect export share across firm types. For instance, in the "Light manufacturing" sector, the ratio of indirect to direct VA exports is $50 \%$ in 2007 , one of the lowest, but the ratio for SOEs is $75 \%$. A casual observation shows that SOEs tend to have a higher indirect export share in sectors that are associated with a lower average indirect export share, such as electronic equipment; while SMEs tend to have a higher indirect export share in industries that have a higher average indirect export share, such as energy and mining, and the financial sector. We will use the upstreamness measures proposed by Antras et al. (2012) to conduct a more systematic analysis below.

\subsubsection{The Domestic Segment of GVCs (Export-related Profits based on the Forward-linkage Approach)}

We also apply our framework to answer an important policy-relevant question: how much profit was generated by exports in China, and how was the export-related profit distributed across different firm types? Similar to our analysis on value added exports, we can attribute export-related profit (the 
operating surplus term in an IO table) accruing to a firm type via direct and indirect exports, respectively. By “direct”, we refer to profits accruing to direct exporters. By "indirect”, we refer to profits accruing to firms that supply goods and services to downstream exporters, through the domestic input-output network. Column (1) in Panel A of Table 4 reports a total of 885 billion RMB profits (about 120 billion USD in 2007 exchange rate) accruing to direct exporters in 2007. Similar to our analysis of value added exports above, this value of profits for direct exporters may underestimate the actual export-induced profits in the domestic economy. Therefore, we also estimate profits accruing to firms that sell inputs and services, directly and indirectly, to exporters in the economy (defined in the same way in Table 2). When both direct and indirect exporters' profits are included (column (2)), total export-related profits increased to 2.3 trillion RMB (about 315 billion USD). As reported in Panel B, direct export-related and total export-related profits for 2010 were 763 billion and 2.2 trillion RMB, respectively. ${ }^{15}$ The decline in both profit measures, despite the fact that value added exports increased between the two years, suggests that the Chinese economy may have become more competitive over time.

How important are export activities in generating profits in the Chinese economy? According to the IO tables, total profits (capital income) of the Chinese economy were about 8 trillion RMB in 2007 and 9.7 trillion RMB in 2010. In other words, if we focus on profit accrued to direct exporters only (i.e., 885 and 763 billion RMB), export generated about 11\% and 8\% of China's total profits in 2007 and 2010, respectively. On the other hand, if we also include profit accrued to firms that also supply intermediate goods and services to exporters, profits that could be attributed to exports increased to about 29\% in 2007 and $23 \%$ in 2010.

(Insert Table 4 here)

Similar to the decomposition of value added exports conducted in Table 2, we can also distribute export-related profits to different firm types. As reported in column (3), we find that FIEs have the highest profit per worker derived from exports (both direct and indirect), while SMEs have the lowest export-related profit per worker. Specifically, profit per worker due to exports was 6140 RMB for FIEs in 2007, 1250 RMB for SOEs, 1720 RMB for LPs, and only 700 RMB for SMEs. Using 2008 firm census data, along with 2007 and 2010 IO tables, we find that export-related profit per worker declined from 1150 RMB in 2007 to 999 RMB in 2010 for the aggregate economy. Those for FIEs and LPs, however, increased to 6440 and $1980 \mathrm{RMB}$, respectively.

Column (4) reports each firm type's share in total export-related profits. SMEs are responsible for $47 \%$ of

${ }^{15}$ Notice that we are still using 2008 firm census to measure aggregate surplus and surplus by firm type. 
the export-related profits in 2007, followed by FIEs that account for 25\%. Given that SMEs hire most of the workers in China (92\% in 2007) and produce over half of the country's GDP (55\%), their low share of total profit implies an uneven distribution of profits across firm types. Once again, we find a small increase in SOEs' share of export-related profit. Consistent with the slight increase in SOEs' share in value added exports, their share of profits increased from $18.5 \%$ in 2007 to $19.2 \%$ in 2010 . Is this supporting evidence for the claim that SOEs have advanced in the Chinese economy at the expense of the private sector? Notice that both FIEs and LPs also experience an increase in their shares of export-related profits. The increase of SOEs' export-related profits was not the sharpest. It went up by $4 \%$, compared to 9\% for FIEs and LPs, respectively. In other words, the entire decline in export-related profits falls on SMEs, as the other three firm types all experienced an increase in profits.

The drastic differences in export-related profits across firm types hide substantial heterogeneity in the channels through which different firm types derive their profits from downstream exports. Column (9) shows that domestic firms (SOEs, LPs, and SMEs) derive most of their export-related profits indirectly. The share of profits that firms derive from indirect export ranges from $61 \%$ for SMEs to $79 \%$ for SOEs. Columns (5) to (8) show that FIEs play a dominant role in exporting for other upstream firms (ranging from 23 to 35\% depending on upstream firm types). Perhaps surprisingly, SMEs also serve as an important channel through which other firms can derive profits from exports (between 11 to 20\%). Panel B shows that from 2007 to 2010, the roles of FIEs in serving as downstream exporters to generate profits for other firm types increased from 28\% in 2007 to 37\% in 2010. Despite an increase in profit shares, SOEs become less important as a channel to pass on export-related profits from downstream exporters to upstream firms. As reported in column (5), the SOE channel, measured as the share of profits generated by indirect exporting, dropped from 9.2\% (Pane A) to 6.3\% (Panel B).

\subsubsection{The Domestic Segment of GVCs (VAX based on the Backward-linkage Approach)}

So far, we have been using the forward-linkage approach, which involves summing up the entries of $\widehat{A}_{V} B \widehat{E}$ (in eq. (7)) horizontally along each row, to estimate direct and indirect value added exports by different types of firms. In this section, we use the backward-linkage approach and ask "For each dollar of Chinese exports (aggregate or by firm type), how much of it is coming from SOEs, FIEs, etc.?” Different from the forward-linkage approach that focuses on the channels through which each firm type's VAX (by sector or at the aggregate) is generated, the backward-linkage approach decomposes each firm type's gross exports into direct VA, indirect VA from the same type, and indirect VA from other firm types. For example, SOEs' gross exports now include not only VA of the SOE exporters themselves, but also domestic VA from all other upstream firm types, including other SOEs, as well as other firm types' 
VA embedded in inputs used to produce those exports. ${ }^{16}$ This decomposition exercise permits an analysis on the distribution of VAX across firm types embedded in each firm type's downstream exports, complementing the forward-linkage approach that focuses on the "paths" of exporting.

By using this backward-linkage VAX measure, we provide another set of results to examine how the domestic VA in Chinese exports is distributed across firm types, and how the distribution changed between 2007 and 2010. As reported in Table 5, of the 10 trillion RMB Chinese gross exports in 2007, 14\% can be attributed to SOEs, directly and indirectly; while the contribution by FIEs, LPs, and SMEs are $18 \%, 7 \%$ and $29 \%$, respectively. The findings of high value added by SOEs and SMEs resonate well with the finding that both types of firms have high VAX, as reported in Table 2. Foreign VA in Chinese exports in 2007 is 32\%. We also decompose each firm type's gross exports into contributions by different firm types' indirect exports. For instance, we find that for each dollar of SOEs' gross exports, SOEs themselves contribute about 39 cents ( 24 cents directly and 15 cents indirectly), followed by 18 cents from SMEs and 10 cents from FIEs. Foreign value added from abroad accounts for 26 cents, lower than its contribution in aggregate export. Notice that the numbers along the diagonal is always the highest compared to other numbers in the same column, suggesting that each firm type contributes the most VA to its own gross exports, compared to other firm types.

(Insert Table 5 here)

The lower panel of Table 5 reveals that while Chinese gross exports increased by only $9.7 \%$ from 2007 to 2010, the contribution of SOEs in terms of VA increased by $14.8 \%$. Specifically, for each dollar of Chinese gross exports, 14.2 cents ultimately came from SOEs in 2007, while 16.3 cents came from them in 2010. SOEs are not the only group that experienced an increase in VA shares between the two years. All three other groups also experienced an increase, at the expense of foreign VA. However, it is the SOEs that experienced the sharpest increase in VA contribution, followed by FIEs that had its VA share increased by $9.2 \%$. Another fact revealed in Table 5 is that SOEs' VA shares increased for exports by all firm types. This is not observed for other firm types. For instance, FIEs' VA shares increased only for FIEs' exports but not for other firm types.

The backward-linkage approach can be used to distribute sectoral DVA in exports into different sources of firm types. Such an exercise provides another perspective to portray the cross-sector pattern of contributions by different firm types. As reported in Table 6, a few sectors have more than 30\% DVA

\footnotetext{
${ }^{16}$ Such a backward-linkage perspective aligns well with case studies of GVC of specific sectors and products, such as the iPod or iPhone examples frequently cited in the literature.
} 
originating from SOEs. In 2007, these sectors include "Mining and Washing of Coal” (SOEs' share in total sector's VAX = 39.98\%), "Extraction of Petroleum and Natural Gas" (49.56\%), "Mining of Non-Ferrous Metal Ores” (32.50), “Processing of Petroleum, Coking and Nuclear Fuel” (44.16), "Smelting and Rolling of Metals" (36.67), "Production and Supply of Electricity and Heat" (52.05). These are obviously "upstream" sectors that provide essential inputs to downstream exporters. In the next section, we will conduct a systematic analysis on SOEs' potential dominance in "upstream” sectors, using Antras et al.'s (2012) measures.

\section{(Insert Table 6 here)}

While SOEs appear to have a dominant position in some sectors, they are not the firm group that has the highest VA shares for most sectors. It is the SMEs that often contribute more than $30 \%$ of VAX in most sectors. In fact, SOEs' VA share exceeded 30\% for only 13 sectors (out of 40 ) compared to 24 for SMEs. For example, SMEs' shares of VAX in "Foods and Tobacco" and "Manufacture of Textile Products" are $60 \%$ and 52\%, respectively. These findings suggest that SMEs have been playing an important role driving Chinese exports. This is consistent with the hypothesis that a lot of SMEs do not export directly, possibly because of high fixed export costs. Instead, they participate actively by supplying intermediate inputs and services to larger downstream exporters. In 2010, the number of sectors in which SOEs' share in VAX exceeded 30\% actually dropped from 13 to 11 . However, in those sectors that SOEs had the highest VAX share in 2007, SOEs' VAX shares have increased substantially. For example, in the “Mining and Washing of Coal” sector, SOEs' VAX share was $40 \%$ in 2007, which increased to 56\% in 2010.

\subsection{Industry Upstreamness by Firm Type}

Table 3 shows a vast heterogeneity in indirect export shares across industries, consistent with the conventional view that non-tradable sectors do not export much and typically participate in exports indirectly. Table 6 further shows that SOEs seem to prevail in "upstream” sectors. These findings hint that SOEs and SMEs derive their large indirect exports through different channels. To analyze these channels more systemically, we use the method proposed by Antras et al. (2012) to measure industry upstreamness. We make two important extensions to the original method. First, given our split IO table, we can measure an industry’s upstreamness by firm size and ownership type. With these measures in hand, we can then examine whether within an industry, some firm types are relatively more upstream on 
average. We construct the upstreamness measure for 40 industries and 6 firm groups. ${ }^{17}$ The second extension is that we relax the proportionality assumptions they make about the allocation of imports and exports in each industry pair. Specifically, our estimated IO coefficients already have imports taken out by explicitly including $\mathrm{A}^{m}$ in our model. When dealing with exports from sector $i$ to sector $j$ by firm type, we use data on exported intermediate inputs from China's customs and assign the bi-sectoral exports to different firm types based on their shares in each IO link in the domestic economy. See the appendix for details. Table A3 in the appendix report the 240 upstreamness measures, along with the industry upstreamness estimated based on the conventional IO table (without any split).

Table 7 reports the top 5 and bottom 5 industry upstreamess measures based on the conventional IO table. By construction, the upstreamness measure ranges between 1 and the maximum number of the industries in the country's IO table. The top 5 most "upstream” industries (out of 40) are "Extraction of Petroleum and Natural Gas”, "Mining of Ferrous Metal Ores”, "Mining and Washing of Coal”, "Production and supply of Electricity and heat”, "Processing of Petroleum, Coking and Nuclear Fuel”. The values of upstreamness for these industries range between 4 and 5, meaning that these industries are on average 4-5 industries away before reaching final consumers. These raw material and energy industries sell intermediate inputs to many other industries, including other upstream industries. They are expected to rank high up in the domestic production network. The bottom 5 "upstream” industries are "Real Estate", “Health and Social service”, "Education”, “Construction industry”, "Public administration and social organization”. They tend to sell final goods and services directly to customers.

(Insert Table 7 here)

By using the split IO table, we can estimate the upstreamness measures for different firm groups. Consistent with the high indirect export ratio, SOEs, particularly the small ones, tend to have the highest upstreamness measure among all firms types within each industry, while SMEs tend to have the lowest upstreamness, particularly in the least upstream industries, among all firm types. Fig. 4 plots the SOEs', FIEs', LPs' and SMEs' upstreamness measures against the industry overall measures, which are estimated using the original aggregate IO table. Most measures for the SOEs (blue squares) are above the 45-degree line, suggesting that SOEs are often more upstream than other firm types within the same industry. SMEs, on the other hand, are often the most “downstream” within industries.

Another way to show that SOEs have a dominant position in the upstream industries is to examine the correlation between the share of SOEs in different aggregate outcomes and industry upstreamness. Fig. 5

17 The original IO table has 42 industries, but we dropped 
shows a positive and (marginally) significant correlation between the share of SOEs in total industry output and industry upstreamness, suggesting that SOEs have a dominant position in upstream industries. Fig. 6 shows a positive and significant relationship between SOEs' share in the industry's gross exports and industry upstreamness. Figs. 7-8 show no particular relationship between upstreamness, output, and exports for SMEs. In sum, these findings confirm that the high VAX ratio for SOEs is partly driven by their dominance in the upstream sectors, while SMEs' high VAX is due to other reasons. One possibility is that exporting is associated with high fixed costs and only large (productive) firms can make sufficiently high export revenue to amortize them. Thus, SMEs tend to export indirectly and have a high VAX ratio.

We use the split IO table from 2010 and estimate the industry measures of upstreamness for different firm types again (see Table A3 in the appendix for the estimates). Fig. 9 shows that for 27 of the 40 industries, the upstreamness measure increased. This finding is exactly the opposite of what recent studies have documented for the U.S., where industries have shown to become more downstream over time (Fally, 2012). If more upstream activities are being offshored from the U.S. to China, our results can provide the "mirror-image” support to Fally (2012).

\section{Concluding remarks}

This paper proposes methods to incorporate firm heterogeneity in the standard IO-table based approach to portray the domestic segment of global supply chains in a country. Using conventional IO tables, firm census data for both manufacturing and service sectors, and constrained optimization techniques, we are able to estimate direct and indirect value added exports (VAX) for different types of firms in China, and decompose a firm type's indirect VAX into different channels through which they are realized.

Based on our split IO table, we find that in China, both state-owned enterprises (SOEs) and small and medium domestic private enterprises (SMEs) have much higher shares of indirect exports and ratios of value-added exports (VAX) to gross exports, compared to foreign-invested and large domestic private firms. Using China's IO tables for 2007 and 2010 respectively, we find evidence of increasing VAX ratios for all firm types, particularly for SOEs. By extending the method proposed by Antras et al. (2012), we find that SOEs are consistently more upstream while SMEs are consistently more downstream within industries. These findings suggest that SOEs still play an important role in shaping China's downstream exports.

Our findings imply that years of privatization have led to the dominance of SOEs, not only large firms, in 
the upstream sectors. While the political economy factors behind such privatization outcomes are beyond the scope of this paper, documenting these unique patterns shed light on understanding China's past and future economic growth. The conventional view is that China's export growth is largely driven by the dynamic labor-intensive private sector, especially the foreign-dominated processing sector. We have documented coherent evidence that SOEs still play a significant role in shaping China's aggregate export patterns and performance.

Whereas SMEs are similar to SOEs in the sense that they also have high value added and indirect export ratios, the sources and the channels behind these similarities appear to be quite different. In addition to the fact that non-state SMEs are more likely to export through other non-state firms, their upstreamness is also lower within industries. This finding suggests that the higher VAX and indirect export share of SMEs are probably due to their higher propensity to sell intermediate inputs and services to other large firms who eventually export, rather than having an upstream position in the domestic production network, as have been enjoyed by SOEs. 


\section{References}

Ahn, J., A. Khandelwal, S.J. Wei (2011) "The Role of Intermediaries in Facilitating Trade," December 2010, Journal of International Economics, 84(1), 73-85.

Antras, P. and D. Chor (2012) "Organizing the Global Value Chain," Harvard University Working Papers.

Antras, P., Costinot, A. (2011) “Intermediated Trade", Quarterly Journal of Economics, 2011, vol. 126, issue 3, pp. 1319-1374.

Antras, P., D. Chor, T. Fally and R. Hillberry (2012) "Measuring the Upstreamness of Production and Trade Flows" forthcoming, American Economic Review Papers and Proceedings, Vol. 102, No. 3, pp. 412-416.

Asiedu, E. and J. Freeman (2007) "The Effect of Globalization on the Performance of Small-and Medium-Sized Enterprises in the United States: Does Owners' Race/Ethnicity Matter?” American Economic Review, Vol. 97, No. 2 (May, 2007), pp. 368-372.

Bernard, A., Jensen, J. Bradford, S. Redding, and P.K. Schott (2007) "Firms in International Trade," Journal of Economic Perspectives, 21(3), pp. 105-130.

Bernard, A., B. Jensen, S. Redding, and P.K. Schott (2010) "Wholesalers and Retailers in U.S. Trade," American Economic Review, 100(2), 408-413.

Branstetter, L. and Nicolas L. (2006) “China's embrace of globalization,” NBER Working Paper.

Brandt, L., Van Biesebroeck, J., and Zhang, Y. (2012). "Creative accounting or creative destruction? Firm-level productivity growth in Chinese manufacturing,” Journal of Development Economic, 97(2), 339-351.

Brooke, K., Meeraus, and Raman (2005) GAMS - User's Guide, Washington, DC: GAMS Development Cooperation.

Chen, X., Cheng, L. K., Fung, K. C., Lau, L. J., Sung, Y. W., Zhu, K., and Duan, Y. (2012) "Domestic value added and employment generated by Chinese exports: A quantitative estimation,” China Economic Review.

Costinot, A., J. Vogel and S. Wang, "Global Supply Chains and Wage Inequality", American Economic Review Papers and Proceedings, forthcoming.

Costinot, A., J. Vogel, and S. Wang (2012) “An Elementary Theory of Global Supply Chains,” Review of Economic Studies, forthcoming.

De La Cruz, J., R. Koopman, Z. Wang, and S.J. Wei (2010) "Estimating Foreign Value-added in Mexico’s Manufacturing Exports.” USITC Working Paper.

Hummels, D., Ishii, J., and Yi, K-M. (2001). "The nature and growth of vertical specialization in world trade.” Journal of International Economics, 54(1), 75-96.

Koopman, R., Z. Wang, and S.J. Wei (2008) "How Much of Chinese Exports is Really Made in China? 
Assessing the Domestic Value-Added When Processing Trade is Pervasive,” NBER Working Paper No. 14109.

Koopman, R., Z. Wang, and S.J. Wei (2012) "Estimating Domestic Content in Exports When Processing Trade Is Pervasive,” Journal of Development Economics, 99:1, pp.178-89.

Koopman, Robert, Zhi Wang and Shang-Jin Wei, 2014, “Tracing Value-added and Double Counting in Gross Exports," American Economic Review, 104(2):459-494. Also available as NBER Working Paper No. 18579.

National Research Council. (2006). Analyzing the U.S. content of imports and the foreign content of exports. Committee on Analyzing the U.S. Content of Imports and the Foreign Content of Exports. Center for Economic, Governance, and International Studies, Division of Behavioral and Social Sciences and Education. Washington, DC: The National Academies Press.

He, D., W. Zhang, G. Han, and T. Wu (2012) "Productivity Growth of the Non-Tradable Sectors in China.” Working Papers, Hong Kong Institute for Monetary Research.

Puzzello, L. (2012) "A Proportionality Assumption and Measurement Biases in the Factor Content of Trade," Journal of International Economics, forthcoming.

Roberto A. E. (2004) "Sources of export success in small- and medium-sized enterprises: the impact of public programs”, International Business Review, Volume 13, Issue 3, June 2004, Pages 383-400.

Song, Z., Storesletten, K., \& Zilibotti, F. (2011) “Growing like China. American Economic Review," 101(1), 196-233.

USITC (2010) "Small and Medium-Sized Enterprises: Characteristics and Performance" Investigation No. 332-510, USITC Publication 4189, November 2010.

Wang, Y., X. Li and X. Liu (2012) “A Model of China's State Capitalism,” HKUST Working Paper.

Wang, Z., S-J Wei and K. Zhu (2013) "Quantifying International Production Sharing at the Bilateral and Sector Level”. NBER Working Paper 19677.

Zhu, X. (2012) “Understanding China’s Growth: Past, Present, and Future,” Journal of Economic Perspective. 
Figure 1: Input-Output table with separate production account for firms by ownerships and size and abroad

\begin{tabular}{|c|c|c|c|c|c|c|c|c|c|c|c|}
\hline & & & \multicolumn{6}{|c|}{ Intermediate use } & \multirow[b]{2}{*}{\begin{tabular}{|l|} 
Domestic \\
Final Use \\
\end{tabular}} & \multirow[b]{2}{*}{ Export } & \multirow[b]{2}{*}{$\begin{array}{c}\text { Total Gross } \\
\text { Output }\end{array}$} \\
\hline & & & $\begin{array}{l}\text { SOE Large } \\
\text { (SL) }\end{array}$ & $\begin{array}{c}\text { SOE SM } \\
(\mathrm{SS})\end{array}$ & $\begin{array}{c}\text { FIE Large } \\
\text { (FL) }\end{array}$ & $\begin{array}{c}\text { FIE SM } \\
(\mathrm{FS})\end{array}$ & $\begin{array}{c}\text { Others Large } \\
(\mathrm{OL})\end{array}$ & $\begin{array}{c}\text { Others SME } \\
(\mathrm{OS})\end{array}$ & & & \\
\hline & & DIM & $1,2, \ldots, \mathrm{N}$ & $1,2, \ldots, \mathrm{N}$ & $1,2, \ldots, \mathrm{N}$ & $1,2, \ldots, \mathrm{N}$ & $1,2, \ldots, \mathrm{N}$ & $1,2, \ldots, \mathrm{N}$ & 1 & 1 & 1 \\
\hline \multirow{6}{*}{$\begin{array}{l}\text { Domestic } \\
\text { Intermediate } \\
\text { Inputs }\end{array}$} & $\begin{array}{l}\text { SOE } \\
\text { Large } \\
(\mathrm{SL})\end{array}$ & \begin{tabular}{c|}
1 \\
$\cdot$ \\
. \\
$\mathrm{N}$
\end{tabular} & $Z^{\mathrm{SL}, \mathrm{SL}}$ & $Z^{\mathrm{SL}, \mathrm{SS}}$ & $Z^{\mathrm{SL}, \mathrm{FL}}$ & $Z^{\mathrm{SL}, \mathrm{FS}}$ & $Z^{\mathrm{SL}, \mathrm{OL}}$ & $\mathrm{Z}^{\mathrm{SL}, \mathrm{OS}}$ & $\mathrm{Y}^{\mathrm{SL}}$ & $\mathrm{E}^{\mathrm{SL}}$ & $X^{S L}$ \\
\hline & $\begin{array}{c}\text { SOE SM } \\
\text { (SS) }\end{array}$ & $\begin{array}{c} \\
\dot{\mathrm{N}} \\
\dot{\mathrm{N}}\end{array}$ & $Z^{\mathrm{SS}, \mathrm{SL}}$ & $Z^{\mathrm{SS}, \mathrm{SS}}$ & $Z^{\mathrm{SS}, \mathrm{FL}}$ & $Z^{\mathrm{SS}, \mathrm{FS}}$ & $Z^{\mathrm{SS}, \mathrm{OL}}$ & $\mathrm{Z}^{\mathrm{SS}, \mathrm{OS}}$ & $\mathrm{Y}^{S S}$ & $\mathrm{E}^{\mathrm{SS}}$ & $\mathrm{X}^{\mathrm{SS}}$ \\
\hline & $\begin{array}{c}\text { FIE Large } \\
\text { (FL) }\end{array}$ & $\begin{array}{c} \\
\dot{\mathrm{N}} \\
\dot{\mathrm{N}}\end{array}$ & $Z^{\mathrm{FL}, \mathrm{SL}}$ & $Z^{\mathrm{FL}, \mathrm{SS}}$ & $Z^{\mathrm{FL}, \mathrm{FL}}$ & $Z^{\mathrm{FL}, \mathrm{FS}}$ & $Z^{\mathrm{FL}, \mathrm{OL}}$ & $\mathrm{Z}^{\mathrm{FL}, \mathrm{OS}}$ & $\mathrm{Y}^{\mathrm{FL}}$ & $\mathrm{E}^{\mathrm{FL}}$ & $\mathrm{X}^{\mathrm{FL}}$ \\
\hline & $\begin{array}{c}\text { FIE } \\
\text { SME } \\
(F S)\end{array}$ & $\begin{array}{c} \\
\dot{\mathrm{N}} \\
\end{array}$ & $Z^{\mathrm{FS}, \mathrm{SL}}$ & $Z^{\mathrm{FS}, \mathrm{SS}}$ & $Z^{\mathrm{FS}, \mathrm{FL}}$ & $Z^{\mathrm{FS}, \mathrm{FS}}$ & $Z^{\mathrm{FS}, \mathrm{OL}}$ & $\mathrm{Z}^{\mathrm{FS}, \mathrm{OS}}$ & $\mathrm{Y}^{\mathrm{FS}}$ & $\mathrm{E}^{\mathrm{FS}}$ & $\mathrm{X}^{\mathrm{FS}}$ \\
\hline & $\begin{array}{l}\text { Others } \\
\text { Large } \\
(\mathrm{OL})\end{array}$ & $\begin{array}{c}1 \\
\dot{\mathrm{N}} \\
\end{array}$ & $Z^{\mathrm{OL}, \mathrm{SL}}$ & $Z^{\mathrm{OL}, \mathrm{SS}}$ & $Z^{\mathrm{OL}, \mathrm{FL}}$ & $Z^{\mathrm{OL}, \mathrm{FS}}$ & $Z^{\mathrm{OL}, \mathrm{OL}}$ & $\mathrm{Z}^{\mathrm{OL}, \mathrm{OS}}$ & $\mathrm{Y}^{\mathrm{OL}}$ & $\mathrm{E}^{\mathrm{OL}}$ & $\mathrm{X}^{\mathrm{OL}}$ \\
\hline & $\begin{array}{l}\text { Others } \\
\text { SME } \\
\text { (OS) }\end{array}$ & $\begin{array}{c}1 \\
\dot{\mathrm{N}} \\
\dot{\mathrm{N}}\end{array}$ & $Z^{\mathrm{OS}, \mathrm{SL}}$ & $Z^{\mathrm{OS}, \mathrm{SS}}$ & $Z^{\mathrm{OS}, \mathrm{FL}}$ & $Z^{\mathrm{OS}, \mathrm{FS}}$ & $Z^{\mathrm{OS}, \mathrm{OL}}$ & $\mathrm{Z}^{\mathrm{OS}, \mathrm{OS}}$ & $\mathrm{Y}^{\mathrm{OS}}$ & $\mathrm{E}^{\mathrm{OS}}$ & $\mathrm{X}^{\mathrm{OS}}$ \\
\hline $\begin{array}{c}\text { Imported } \\
\text { Intermediate } \\
\text { Inputs }\end{array}$ & $\begin{array}{l}\text { Abroad( } \\
\text { F) }\end{array}$ & $\begin{array}{c}1 \\
\dot{.} \\
\dot{\mathrm{N}}\end{array}$ & $Z^{\mathrm{F}, \mathrm{SL}}$ & $Z^{\mathrm{F}, \mathrm{SS}}$ & $Z^{\mathrm{F}, \mathrm{FL}}$ & $Z^{\mathrm{F}, \mathrm{FS}}$ & $Z^{\mathrm{F}, \mathrm{OL}}$ & $\mathrm{Z}^{\mathrm{F}, \mathrm{OS}}$ & $\mathrm{Y}^{\mathrm{F}}$ & & M \\
\hline \multicolumn{2}{|c|}{ Value-added } & 1 & $V^{\mathrm{SL}}$ & $V^{\mathrm{SS}}$ & $V^{\mathrm{FL}}$ & $V^{\mathrm{FS}}$ & $V^{\mathrm{OL}}$ & $V^{\mathrm{OS}}$ & & & \\
\hline \multicolumn{2}{|c|}{ Total Gross Output } & 1 & $\left(\mathrm{X}^{\mathrm{SL}}\right)^{\mathrm{T}}$ & $\left(X^{S S}\right)^{\top}$ & $\left(\mathrm{X}^{\mathrm{FL}}\right)^{\top}$ & $\left(X^{F S}\right)^{\top}$ & $\left(\mathrm{X}^{\mathrm{OL}}\right)^{\top}$ & $\left(\mathrm{X}^{\mathrm{OS}}\right)^{\top}$ & & & \\
\hline
\end{tabular}




\section{Appendix A}

\section{Extending the method by Antras et al. (2012) to measure industry upstreamness}

To measure industry upstream based on our IO table with 6 sub-accounts, we need to modify the method proposed by Antras et al. (2012). First, we construct a 42x42 matrix for each firm type g1 with the following elements

$$
\delta_{i j}^{g 1}=\frac{\sum_{p} \mathrm{a}_{i j}^{g 1, g 2} \mathrm{x}_{j}^{g 2}+E_{i j}^{g 1}}{\mathrm{X}_{i}^{g 1}}
$$

Where superscripts $g 1, g 2=(S L, S S, F L, F S, O L, O S)$ represent 6 firm types, $\mathrm{a}_{i j}^{g 1, g 2}$ is the IO coefficient between a pair of firm-type-sector discussed in Section 2 in the text. $\mathrm{X}_{j}^{g 1}$ and $\mathrm{X}_{j}^{g 2}$ are gross output by group g1 and g2 in sector $j$, respectively. $E_{i j}^{g 1}$ represents exports from sector $i$ by firm type g1 used in sector $j$ abroad.

When computing industry upstreamness, Antras et al. (2012) assume that the share of imports (and exports) of sector $i$ that is used by sector $j$ is the same as the share of domestic intermediate inputs of sector $i$ used by sector $j$. We improve upon their computation by relaxing both of these assumptions. First, in eq. (A1), we do not need to subtract imports from total intermediate inputs. It is because when we estimate our extended IO model, we already make the corresponding adjustment to deal with imported materials by having a separate $A^{m}$ matrix. In other words, our IO coefficients, $a_{i j}^{g 1, g 2}$, do not include imported intermediate inputs. Thus, we do not need to make the proportionality assumptions as Antras et al. (2012) to exclude imports from domestic intermediate inputs in our computation of upstreamness.

Second, when computing $E_{i j}^{g 1}$, we use data of exported intermediate inputs at the sector-pair level (i-j) from China's customs. To assign exported intermediate inputs to each firm type, we use the share of each supplier's firm type in domestic inter-sector transaction volume (i.e., $\left.\frac{\sum_{g 2} A_{i j}^{g 1, g 2}}{\sum_{g_{1}, g_{2}} A_{i j}^{g 1, g 2}}\right)$ as the weight. For sectors that we do not have exported intermediate inputs from China's Customs (most of them are service sectors), we follow Antras et al. (2012) and make the same proportionality assumption to obtain $E_{i j}^{g 1}$ 。

We also adjust for the change in inventory at the sector level carefully. First, we obtain inventory by firm type and sector. Then following the approach proposed by Antras et al., (2012), we subtract inventory from $X_{i}^{g 1}$ in eq. (A1). After obtaining a $42 x 42$ block matrix of $\delta_{\mathrm{ij}}^{g 1}$, we use eq. (4) in Antras et al. (2012) to compute upstreamness by sector and firm type. 
TABLE 1: Estimated Contribution in Main Economic Activities by Firm Type

\begin{tabular}{|c|c|c|c|c|c|c|c|}
\hline Firm Type & $\begin{array}{l}\text { Number of } \\
\text { Firms (08) }\end{array}$ & $\begin{array}{c}\text { Value } \\
\text { Added (08) }\end{array}$ & $\begin{array}{l}\text { Employmen } \\
\text { t (08) }\end{array}$ & $\begin{array}{c}\text { Gross } \\
\text { Exports } \\
(07)\end{array}$ & $\begin{array}{l}\text { Value Added } \\
\text { Exports (07) }\end{array}$ & $\begin{array}{c}\text { Gross } \\
\text { Exports } \\
(10)\end{array}$ & $\begin{array}{l}\text { Value Added } \\
\text { Exports (10) }\end{array}$ \\
\hline \multicolumn{8}{|l|}{ Panel A: Share (\%) } \\
\hline SOE & 4.73 & 19.16 & 9.24 & 12.07 & 20.81 & 9.40 & 22.02 \\
\hline FIE & 3.01 & 16.34 & 6.49 & 49.47 & 26.50 & 56.65 & 26.67 \\
\hline Large Enterprise (LP) & 0.22 & 9.91 & 4.82 & 10.08 & 10.35 & 10.41 & 10.10 \\
\hline Small and Medium Private (SME) & 92.04 & 54.58 & 79.45 & 28.38 & 42.34 & 23.54 & 41.21 \\
\hline \multicolumn{8}{|c|}{ Panel B: Value (Billion for values; million for employment) } \\
\hline SOE & 188829 & 5098.20 & 71.16 & 1230.94 & 1445.75 & 1051.85 & 1820.57 \\
\hline FIE & 120073 & 4348.44 & 49.94 & 5045.69 & 1841.05 & 6340.14 & 2205.26 \\
\hline Large Enterprise (LP) & 8836 & 2637.43 & 37.09 & 1028.06 & 719.12 & 1164.47 & 834.88 \\
\hline Small and Medium Private (SME) & 3674676 & 14520.31 & 611.71 & 2894.76 & 2941.58 & 2634.63 & 3407.06 \\
\hline Total & 3992414 & 26604.38 & 769.91 & 10199.79 & 6947.49 & 11191.10 & 8268 \\
\hline
\end{tabular}

Note: Data on value added and employment are from China's National Bureau of Statistics (NBS) firm census in 2008. Data on gross exports and value added exports are computed based on 2007 IO tables. 
TABLE 2: Indirect Exports via Different Firm Types

\begin{tabular}{|c|c|c|c|c|c|c|c|c|}
\hline \multirow[t]{2}{*}{ Panel A: 2007} & \multirow{2}{*}{$\begin{array}{l}\text { Value Added Exports } \\
\qquad \text { (Bil RMB) } \\
\text { via }\end{array}$} & \multicolumn{4}{|c|}{ Share of Indirect VAX (\%) } & \multicolumn{3}{|c|}{$\begin{array}{l}\text { VA Exp/ } \\
\text { Gross Exp } \\
\text { (VAXR) } \\
\end{array}$} \\
\hline & & SOE & FIE & LGO & SMO & Total & & \\
\hline SOE & 1446 & 13.14 & 35.27 & 10.94 & 20.19 & 79.54 & 1.17 & \\
\hline FIE & 1841 & 6.56 & 23.35 & 5.72 & 10.68 & 46.31 & 0.36 & \\
\hline Large Enterprise (LP) & 719 & 11.13 & 32.02 & 9.77 & 19.32 & 72.24 & 0.70 & \\
\hline Small and Medium Private (SME) & 2942 & 7.66 & 26.70 & 7.22 & 21.65 & 63.23 & 1.02 & \\
\hline Total & 6947 & 8.87 & 28.15 & 7.86 & 18.20 & 63.07 & 0.68 & \\
\hline Panel B: 2010 & & & & & & & & $\begin{array}{l}\text { Change } \\
\text { relative to } \\
2007(\%) \\
\end{array}$ \\
\hline$\overline{\mathrm{SOE}}$ & 1821 & 9.18 & 43.65 & 10.50 & 16.78 & 80.10 & 1.73 & 47.37 \\
\hline FIE & 2205 & 3.86 & 26.40 & 5.18 & 7.71 & 43.15 & 0.35 & -4.67 \\
\hline Large Enterprise (LP) & 835 & 6.98 & 39.35 & 9.05 & 14.92 & 70.30 & 0.72 & 2.50 \\
\hline Small and Medium Private (SME) & 3407 & 5.60 & 38.77 & 8.05 & 20.83 & 73.25 & 1.29 & 27.26 \\
\hline Total & 8268 & 6.06 & 36.60 & 7.93 & 15.84 & 66.43 & 0.74 & 8.46 \\
\hline
\end{tabular}

Note: Authors' estimation based on data from I/O tables for 2007 and 2010. Both from China's NBS. 
Table 3: Indirect VAX/ Total VAX (4 types; 14 industries) (\%)

\begin{tabular}{|c|c|c|c|c|c|}
\hline \multicolumn{6}{|l|}{ Panel A: 2007} \\
\hline Industry & All & SOE & FIE & LP & SME \\
\hline$\overline{\text { Energy and mining }}$ & 94.03 & 94.57 & 92.30 & 93.01 & 94.58 \\
\hline Metal and non-metallic mineral extraction & 90.14 & 89.15 & 88.18 & 92.17 & 91.17 \\
\hline Light manufacturng & 49.61 & 74.83 & 36.87 & 58.18 & 51.70 \\
\hline Petrochemical & 74.89 & 87.58 & 62.67 & 75.69 & 79.79 \\
\hline Metal and non-metal processing & 67.29 & 68.87 & 69.00 & 75.37 & 60.58 \\
\hline Machinery and equipment & 47.02 & 72.52 & 36.86 & 53.35 & 46.90 \\
\hline Electronic equipment & 20.75 & 45.45 & 16.71 & 34.41 & 36.29 \\
\hline Other manufacturing & 76.35 & 59.75 & 29.67 & 36.68 & 87.02 \\
\hline Electricity, gas and water supply & 99.41 & 99.51 & 99.56 & 98.85 & 98.95 \\
\hline Building industry & 33.63 & 33.18 & 35.94 & 33.39 & 33.38 \\
\hline Transportation and warehousing & 52.87 & 59.78 & 87.92 & 90.06 & 40.50 \\
\hline Wholesale and retail trade & 42.72 & 72.22 & 82.72 & 76.36 & 24.26 \\
\hline Financial sector & 98.18 & 97.94 & 97.82 & 97.78 & 98.51 \\
\hline Other Services & 66.02 & 75.35 & 79.31 & 80.82 & 45.23 \\
\hline Total & 63.07 & 79.54 & 46.31 & 72.24 & 63.23 \\
\hline \multicolumn{6}{|l|}{ Panel B: 2010} \\
\hline Industry & All & SOE & FIE & LP & SME \\
\hline Energy and mining & 0.97 & 0.96 & 0.93 & 0.97 & 0.99 \\
\hline Metal and non-metallic mineral extraction & 0.95 & 0.98 & 0.82 & 1.00 & 0.94 \\
\hline Light manufacturng & 0.54 & 0.92 & 0.32 & 0.61 & 0.68 \\
\hline Petrochemical & 0.74 & 0.80 & 0.56 & 0.78 & $\mathbf{0 . 8 8}$ \\
\hline Metal and non-metal processing & 0.73 & 0.76 & 0.56 & 0.79 & 0.83 \\
\hline Machinery and equipment & 0.48 & 0.72 & 0.34 & 0.48 & 0.66 \\
\hline Electronic equipment & 0.32 & 0.72 & 0.25 & 0.46 & 0.72 \\
\hline Other manufacturing & 0.55 & 0.93 & 0.45 & 0.67 & 0.65 \\
\hline Electricity, gas and water supply & 0.99 & 0.99 & 1.00 & 0.99 & 1.00 \\
\hline Building industry & 0.18 & 0.28 & 0.77 & 0.27 & 0.10 \\
\hline Transportation and warehousing & 0.69 & 0.71 & 0.74 & 0.91 & 0.66 \\
\hline Wholesale and retail trade & 0.46 & 0.53 & 0.61 & 0.56 & 0.38 \\
\hline Financial sector & 0.97 & 0.97 & 0.97 & 0.98 & 0.96 \\
\hline Other Services & 0.70 & 0.72 & 0.78 & 0.87 & 0.61 \\
\hline Total & 0.66 & 0.80 & 0.43 & 0.70 & 0.73 \\
\hline
\end{tabular}

Note: Authors' estimation based on data from 2007 and 2010 IO tables from China's NBS. Italic fonts indicate industries that have indirect export share exeeding $90 \%$. Bolded face denotes the highest among the four ownership types within the industry. 
TABLE 4: Export-related Profits via Different Firm Types

\begin{tabular}{|c|c|c|c|c|c|c|c|c|c|c|}
\hline \multirow[t]{3}{*}{ Panel A: 2007} & \multirow{3}{*}{$\begin{array}{l}\text { Profits accrued to } \\
\text { direct exporters } \\
\text { (billion RMB) }\end{array}$} & \multirow{3}{*}{$\begin{array}{c}\text { Total export- } \\
\text { related profits } \\
\text { (billion RMB) }\end{array}$} & \multirow{3}{*}{$\begin{array}{c}\begin{array}{c}\text { Exp-related } \\
\text { profits per worker } \\
(' 000)\end{array} \\
(3)\end{array}$} & \multirow{3}{*}{$\begin{array}{l}\% \text { of total } \\
\text { exp-related } \\
\text { profits } \\
(4)\end{array}$} & \multicolumn{6}{|c|}{ Share of profits through indirect exporting (\%) } \\
\hline & & & & & & (5) & (6) & (7) & (8) & (9) \\
\hline & & & & & via & SOE & FIE & LP & SME & Total \\
\hline SOE & 89 & 427 & 1.25 & 18.51 & & 13.32 & 35.32 & 10.95 & 19.57 & 79.17 \\
\hline FIE & 307 & 568 & 6.14 & 24.60 & & 6.50 & 23.26 & 5.66 & 10.59 & 46.01 \\
\hline Large Enterprise (LP) & 64 & 232 & 1.72 & 10.06 & & 11.19 & 31.99 & 9.90 & 19.40 & 72.48 \\
\hline Small and Medium Private (SME) & 425 & 1081 & 0.70 & 46.82 & & 8.57 & 26.30 & 7.50 & 18.29 & 60.66 \\
\hline Total & 885 & 2308 & 1.15 & 100.00 & & 9.20 & 27.79 & 7.93 & 16.75 & 61.67 \\
\hline \multicolumn{11}{|l|}{ Panel B: 2010} \\
\hline SOE & 86 & 427 & 1.21 & 19.23 & & 9.16 & 44.04 & 10.53 & 16.13 & 79.85 \\
\hline FIE & 322 & 594 & 6.44 & 26.77 & & 4.24 & 27.56 & 5.73 & 8.27 & 45.80 \\
\hline Large Enterprise (LP) & 74 & 244 & 1.98 & 10.99 & & 7.02 & 39.07 & 9.14 & 14.60 & 69.83 \\
\hline Small and Medium Private (SME) & 281 & 954 & 0.46 & 43.01 & & 6.14 & 39.10 & 7.90 & 17.36 & 70.49 \\
\hline Total & 763 & 2218 & 0.99 & 100.00 & & 6.31 & 36.96 & 7.96 & 14.39 & 65.61 \\
\hline
\end{tabular}

Note: Data on aggregate profits and those by firm type (col 2) are based on 2008 firm census. Profits related to indirect exports and its decomposition are estimated using data from IO tables for 2007 and 2010. 
TABLE 5: Gross Exports and Distribution of the Source of VAX (Backward-linkage Approach)

\begin{tabular}{|c|c|c|c|c|c|c|c|}
\hline$\underline{\underline{2007}}$ & & Total & & $\overline{\mathrm{SOE}}$ & 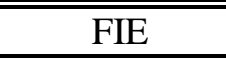 & LP & SME \\
\hline Gross Exports & & 10199 & & 1231 & 5046 & 1028 & 2895 \\
\hline \multirow{5}{*}{$\begin{array}{c}\text { VA Contribution } \\
\text { (\%) }\end{array}$} & SOE & 14.17 & & $\begin{array}{c}39.46 \\
(24.03,15.43)\end{array}$ & 10.11 & 15.38 & 10.08 \\
\hline & FIE & 18.05 & & 9.81 & 28.11 & 10.25 & 6.79 \\
\hline & LP & 7.05 & & 6.50 & $\begin{array}{c}(19.59,8.52) \\
4.56\end{array}$ & $\begin{array}{c}26.25 \\
(19.42,6.83)\end{array}$ & 4.80 \\
\hline & SME & 28.84 & & 18.30 & 15.56 & 20.66 & $\begin{array}{c}59.37 \\
(37.37,22.00)\end{array}$ \\
\hline & Abroad & 31.88 & & 25.92 & 41.66 & 27.47 & 18.95 \\
\hline 2010 & & Total & $\begin{array}{l}\text { ange relat } \\
\text { to } 07\end{array}$ & SOE & FIE & LP & SME \\
\hline Gross Exports & & 11191 & 9.72 & 1052 & 6340 & 1164 & 2635 \\
\hline \multirow{5}{*}{$\begin{array}{c}\text { VA Contribution } \\
(\%)\end{array}$} & SOE & 16.27 & 14.77 & $\begin{array}{c}50.32 \\
(34.44,15.89)\end{array}$ & 12.53 & 16.41 & 11.60 \\
\hline & FIE & 19.71 & 9.17 & 8.09 & $\begin{array}{c}28.95 \\
(19.77,9.18)\end{array}$ & 9.82 & 6.46 \\
\hline & LP & 7.46 & 5.81 & 5.54 & 5.18 & $\begin{array}{c}27.78 \\
(21.29,6.49)\end{array}$ & 4.73 \\
\hline & SME & 30.44 & 5.56 & 18.14 & 20.83 & 23.56 & $\begin{array}{c}61.53 \\
(34.59,26.93)\end{array}$ \\
\hline & Abroad & 26.12 & -18.07 & 17.90 & 32.50 & 22.42 & 15.69 \\
\hline
\end{tabular}

Note: Estimation based 2007 and 2010 IO Table. Numbers in brackets are direct and indirect VA export share, respectively, 


\begin{tabular}{|c|c|c|c|c|c|c|c|c|c|c|c|}
\hline \multirow{3}{*}{$\begin{array}{l}\text { Sector } \\
\# \\
\end{array}$} & \multirow{3}{*}{ Sector } & \multicolumn{5}{|c|}{2007} & \multicolumn{5}{|c|}{$\underline{2010}$} \\
\hline & & \multicolumn{4}{|c|}{ Share in Domestic VA (\%) } & \multirow[t]{2}{*}{$\begin{array}{l}\text { DVA share } \\
>30 \%\end{array}$} & \multicolumn{4}{|c|}{ Share in Domestic VA (\%) } & \multirow[t]{2}{*}{$\begin{array}{l}\text { DVA share } \\
\quad>30 \% \\
\end{array}$} \\
\hline & & SOE & FIE & LP & SME & & SOE & FIE & LP & SME & \\
\hline 2 & Mining and Washing of Coal & 39.98 & 17.57 & 13.93 & 28.52 & SOE & 55.60 & 7.64 & 16.67 & 20.09 & SOE \\
\hline 3 & Extraction of Petroleum and Natural Gas & 49.56 & 16.52 & 23.31 & 10.61 & SOE & 61.64 & 10.52 & 14.37 & 13.47 & SOE \\
\hline 4 & Mining of Ferrous Metal Ores & 27.17 & 21.78 & 7.10 & 43.95 & SME & 27.19 & 12.95 & 7.15 & 52.71 & SME \\
\hline 5 & Mining of Non-Ferrous Metal Ores & 32.50 & 24.00 & 12.91 & 30.58 & SOE, SME & 25.67 & 17.53 & 7.59 & 49.21 & SME \\
\hline 6 & Foods and Tobacco & 15.56 & 17.32 & 7.25 & 59.86 & SME & 13.34 & 17.90 & 6.58 & 62.18 & SME \\
\hline 7 & $\begin{array}{l}\text { Manufacture of Textile Products } \\
\text { Wearing apparel, leather, fur, down and }\end{array}$ & 15.34 & 22.60 & 10.51 & 51.55 & SME & 13.56 & 23.04 & 10.20 & 53.20 & SME \\
\hline 8 & $\begin{array}{l}\text { related products } \\
\text { Processing of wood and Manufacture of }\end{array}$ & 14.53 & 32.29 & 8.76 & 44.41 & FIE. SME & 13.90 & 28.71 & 9.08 & 48.32 & SME \\
\hline 9 & $\begin{array}{l}\text { Furniture } \\
\text { Paper Products and Articles for Culture, }\end{array}$ & 16.01 & 20.61 & 9.25 & 54.13 & SME & 19.13 & 26.47 & 8.76 & 45.64 & SME \\
\hline 10 & $\begin{array}{l}\text { Education and Sports Activities } \\
\text { Processing of Petroleum, Coking and }\end{array}$ & 16.07 & 23.26 & 7.79 & 52.88 & SME & 17.12 & 36.05 & 7.27 & 39.56 & FIE, SME \\
\hline 11 & Nuclear Fuel & 44.16 & 17.63 & 15.57 & 22.64 & SOE & 53.60 & 13.27 & 17.64 & 15.49 & SOE \\
\hline 12 & Manufacture of Chemical Products & 20.80 & 26.23 & 10.61 & 42.36 & SME & 24.01 & 26.92 & 11.36 & 37.71 & SME \\
\hline 13 & Manufacture of non-ferrous metal products & 22.76 & 16.48 & 9.15 & 51.60 & SME & 24.41 & 25.88 & 11.00 & 38.71 & SME \\
\hline 14 & Smelting and Rolling of metals & 36.67 & 14.04 & 19.08 & 30.21 & SOE, SME & 38.12 & 16.25 & 15.62 & 30.01 & SOE, SME \\
\hline 15 & $\begin{array}{l}\text { Manufacture of Metal Products } \\
\text { Manufacture of General Purpose and Special }\end{array}$ & 22.88 & 19.25 & 12.02 & 45.85 & SME & 25.36 & 29.05 & 11.80 & 33.79 & SME \\
\hline 16 & Purpose Machinery & 20.98 & 26.46 & 11.43 & 41.14 & SME & 23.46 & 29.47 & 12.31 & 34.77 & SME \\
\hline 17 & $\begin{array}{l}\text { Manufacture of Transport Equipment } \\
\text { Manufacture of Electrical Machinery and }\end{array}$ & 25.58 & 29.49 & 15.85 & 29.07 & None & 24.71 & 29.44 & 15.25 & 30.60 & SME \\
\hline 18 & Equipment & 23.09 & 28.44 & 14.10 & 34.37 & SME & 22.80 & 31.43 & 12.87 & 32.90 & FIE, SME \\
\hline 19 & $\begin{array}{l}\text { Manufacture of Communication Equipment, } \\
\text { computers and Other Electronic Equipment } \\
\text { Manufacture of Measuring Instruments and }\end{array}$ & 16.17 & 55.43 & 8.09 & 20.31 & FIE & 17.14 & 42.92 & 9.35 & 30.59 & FIE, SME \\
\hline 20 & Machinery for Office Work & 25.39 & 33.29 & 13.79 & 27.53 & FIE & 18.58 & 44.16 & 9.59 & 27.66 & FIE \\
\hline 21 & Handicrafts and other Manufacturing & 17.25 & 26.26 & 11.71 & 44.78 & SME & 10.84 & 41.80 & 6.93 & 40.44 & FIE, SME \\
\hline 22 & Scrap and Waste & 1.94 & 1.25 & 0.78 & 96.03 & SME & - & - & - & - & None \\
\hline 23 & production and supply of Electricity and heat & 52.05 & 13.59 & 11.56 & 22.80 & SOE & 64.01 & 7.15 & 6.44 & 22.40 & SOE \\
\hline
\end{tabular}


TABLE 6 (cont')

\begin{tabular}{|c|c|c|c|c|c|c|c|c|c|c|c|}
\hline \multirow[b]{2}{*}{$\begin{array}{l}\text { Sector } \\
\#\end{array}$} & \multirow[b]{2}{*}{ Sector } & \multicolumn{5}{|c|}{$\underline{\underline{2007}}$} & \multicolumn{5}{|c|}{$\underline{\underline{2010}}$} \\
\hline & & \multicolumn{4}{|c|}{ Share in Domestic VA (\%) } & \multirow{2}{*}{$\begin{array}{c}\text { DVA share } \\
>30 \% \\
\text { None }\end{array}$} & \multicolumn{4}{|c|}{ Share in Domestic VA (\%) } & \multirow{2}{*}{$\begin{array}{c}\text { DVA share } \\
>30 \% \\
\text { None }\end{array}$} \\
\hline 24 & Production and Supply of Gas & - & - & - & - & & - & - & - & - & \\
\hline 25 & Production and Supply of Water & - & - & - & - & None & - & - & - & - & None \\
\hline 26 & construction industry & 29.70 & 17.39 & 13.40 & 39.51 & SME & 25.31 & 9.70 & 9.75 & 55.24 & SME \\
\hline 27 & Transportation and warehousing & 32.17 & 7.58 & 5.00 & 55.25 & SOE, SME & 38.32 & 9.12 & 6.02 & 46.54 & SOE, SME \\
\hline 28 & Post service & 30.21 & 30.79 & 12.14 & 26.86 & SOE, FIE & 65.71 & 11.71 & 5.53 & 17.05 & SOE \\
\hline 29 & IT industry & 30.41 & 31.96 & 13.92 & 23.70 & SOE, FIE & 27.80 & 36.17 & 9.23 & 26.80 & FIE \\
\hline 30 & wholesale and retailing & 13.85 & 7.10 & 4.96 & 74.09 & SME & 23.48 & 8.82 & 8.12 & 59.58 & SME \\
\hline 31 & Hotels and Catering Services & 19.21 & 16.08 & 8.29 & 56.42 & SME & 19.16 & 13.18 & 6.08 & 61.58 & SME \\
\hline 32 & Finance & 34.88 & 16.08 & 10.94 & 38.10 & SOE, SME & 27.85 & 6.97 & 2.58 & 62.61 & SME \\
\hline 33 & Real Estate & - & - & - & - & None & - & - & - & - & - \\
\hline 34 & Leasing and commerce service & 22.12 & 15.43 & 8.40 & 54.05 & SME & 30.00 & 15.85 & 6.87 & 47.28 & SOE, SME \\
\hline 35 & Research and test development industry & 33.83 & 22.61 & 15.96 & 27.60 & SOE & 38.35 & 14.94 & 10.52 & 36.19 & SOE, SME \\
\hline 36 & Polytechnic Services & - & - & - & - & None & - & - & - & - & None \\
\hline 37 & Water, environment and public facilities & - & - & - & - & None & - & - & - & - & None \\
\hline 38 & Resident and Other Services & 26.16 & 21.35 & 12.79 & 39.70 & SME & 15.45 & 10.26 & 10.22 & 64.07 & SME \\
\hline 39 & Education & 26.88 & 20.64 & 14.81 & 37.67 & SME & 18.69 & 10.46 & 16.89 & 53.95 & SME \\
\hline 40 & Health and Social service & 31.85 & 20.85 & 14.58 & 32.72 & SOE, SME & 31.79 & 12.40 & 14.20 & 41.61 & SOE, SME \\
\hline 41 & Culture , Sports and entertainment & 34.84 & 21.85 & 14.51 & 28.80 & SOE & 48.37 & 9.05 & 4.51 & 38.08 & SOE, SME \\
\hline
\end{tabular}


Table 7: Top and Bottom Industry Upstreamness

\begin{tabular}{|c|c|c|c|c|c|}
\hline \multirow[b]{2}{*}{ Code Industry } & \multirow[t]{2}{*}{ All } & \multicolumn{4}{|c|}{ Вy Type } \\
\hline & & SOE & FIE & LP & SME \\
\hline \multicolumn{6}{|c|}{$\underline{2007}$} \\
\hline \multicolumn{6}{|l|}{ Top 5} \\
\hline 3 Extraction of Petroleum and & 5.09 & 6.02 & 5.31 & 4.99 & 4.39 \\
\hline 4 Mining of Ferrous Metal Ores & 5.03 & 5.80 & 5.79 & 5.27 & 4.30 \\
\hline 2 Mining and Washing of Coal & 4.90 & 5.72 & 5.35 & 4.91 & 3.98 \\
\hline $\begin{array}{l}23 \text { Production and supply of } \\
\text { Electricity and heat }\end{array}$ & 4.46 & 5.09 & 4.69 & 4.35 & 3.75 \\
\hline $\begin{array}{l}11 \text { Processing of Petroleum, Coking } \\
\text { and Nuclear Fuel }\end{array}$ & 4.27 & 5.22 & 4.77 & 4.04 & 3.59 \\
\hline \multicolumn{6}{|l|}{ Bottom 5} \\
\hline 33 Real Estate & 1.67 & 2.65 & 2.58 & 1.53 & 1.22 \\
\hline 40 Health and Social service & 1.26 & 1.50 & 1.48 & 1.48 & 1.08 \\
\hline 39 Education & 1.20 & 1.43 & 1.46 & 1.31 & 1.05 \\
\hline 26 Construction industry & 1.06 & 1.08 & 1.24 & 1.08 & 1.02 \\
\hline $\begin{array}{l}42 \text { Public administration and social } \\
\text { organization }\end{array}$ & 1.02 & 1.05 & 1.10 & 1.05 & 1.01 \\
\hline
\end{tabular}

$\underline{\text { Top } 5}$

3 Extraction of Petroleum and Natural Gas

$\underline{2010}$

2 Mining and Washing of Coal

4 Mining of Ferrous Metal Ores

23 production and supply of Electricity and heat

11 Processing of Petroleum, Coking and Nuclear Fuel

$\begin{array}{lllll}5.22 & 6.31 & 4.91 & 5.32 & 4.22 \\ 5.04 & 5.66 & 5.84 & 5.24 & 4.68 \\ 5.13 & 5.86 & 5.09 & 5.04 & 4.68 \\ 4.60 & 5.31 & 4.30 & 4.14 & 3.85 \\ 4.38 & 5.57 & 5.08 & 4.19 & 4.06\end{array}$

\section{Bottom 5}

33 Real Estate

40 Health and Social service

\begin{tabular}{lllll}
1.60 & 3.41 & 3.00 & 1.46 & 1.22 \\
1.20 & 1.34 & 3.03 & 1.37 & 1.05 \\
1.09 & 1.39 & 1.77 & 1.11 & 1.02 \\
1.06 & 1.10 & 2.83 & 1.09 & 1.02 \\
1.03 & 1.11 & 2.50 & 1.13 & 1.01 \\
\hline
\end{tabular}

Note: Authors' estimation based on data from 2007 I/O tables. Bolded face denotes the highest in each row for the top 5 , and the lowest in each row for the bottom 5 . there are altogether 40 industries. 
Figure 2: Firm Average Export Intensity

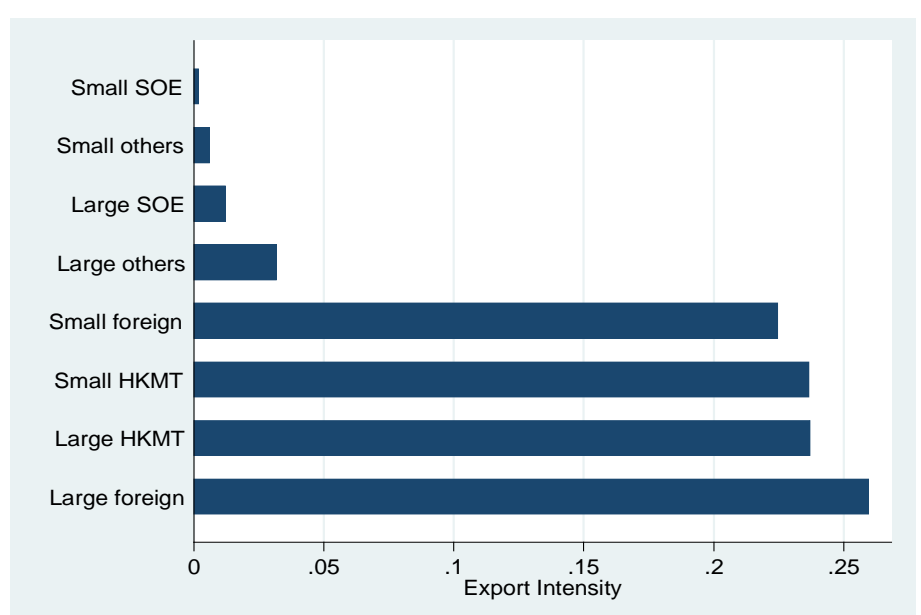

Source: China's National Bureau of Statistics Firm Census Data (2008)

Figure 3: Firm Average Value Added to Output Ratio

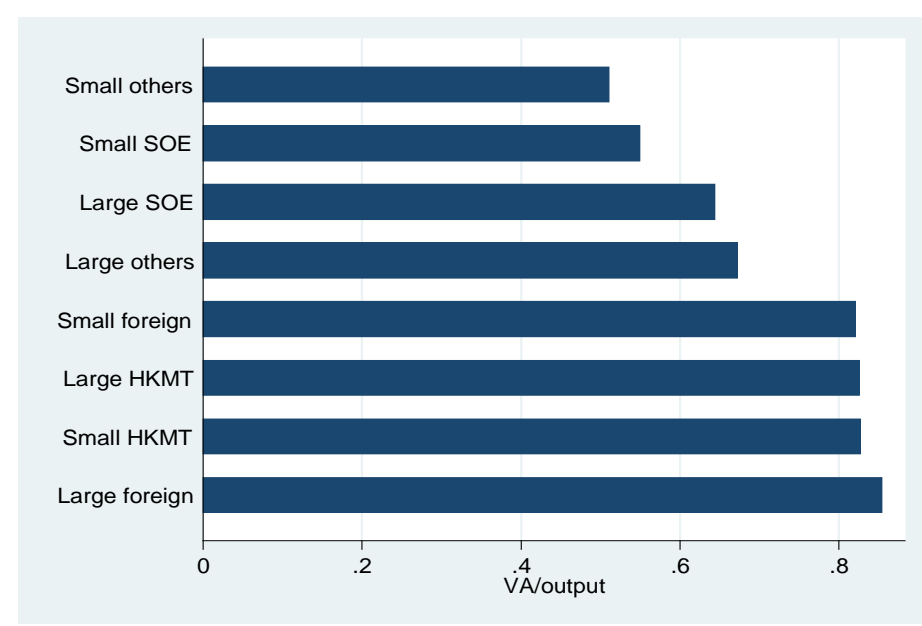

Source: China's National Bureau of Statistics Firm Census Data (2008) 
Figure 4: Upstreamness of by Ownership Type

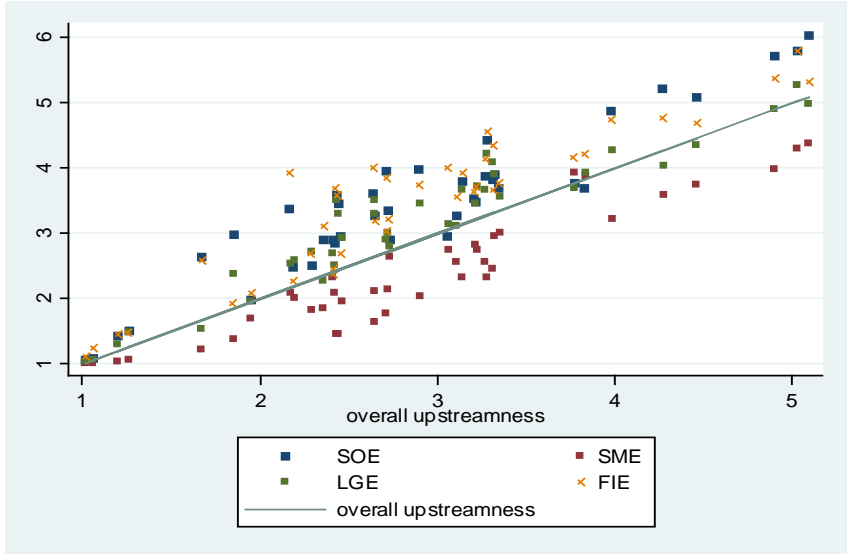

Figure 5: Share of SOEs in Sector Value Added and Sector Upstreamness

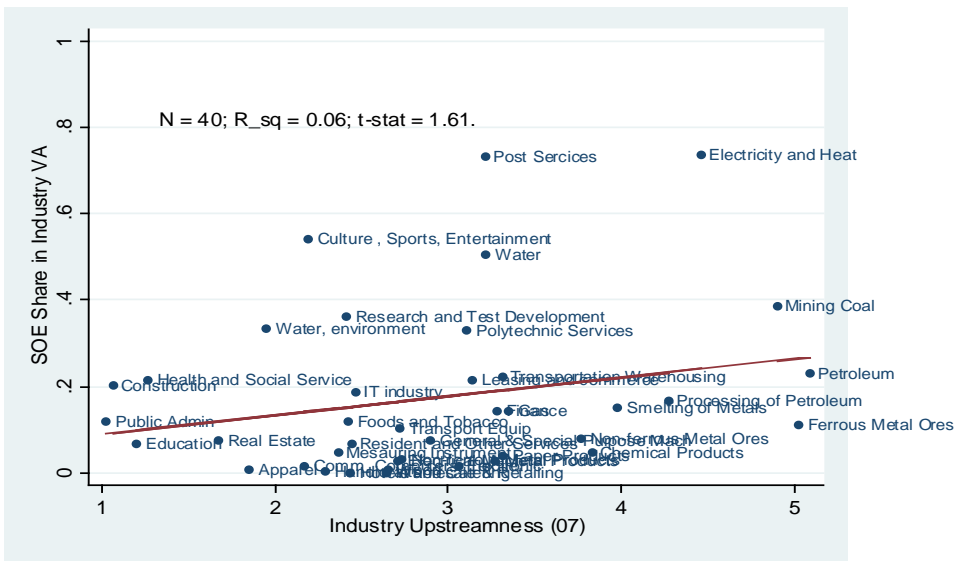

Figure 6: Share of SOEs in Sector Exports and Sector Upstreamness

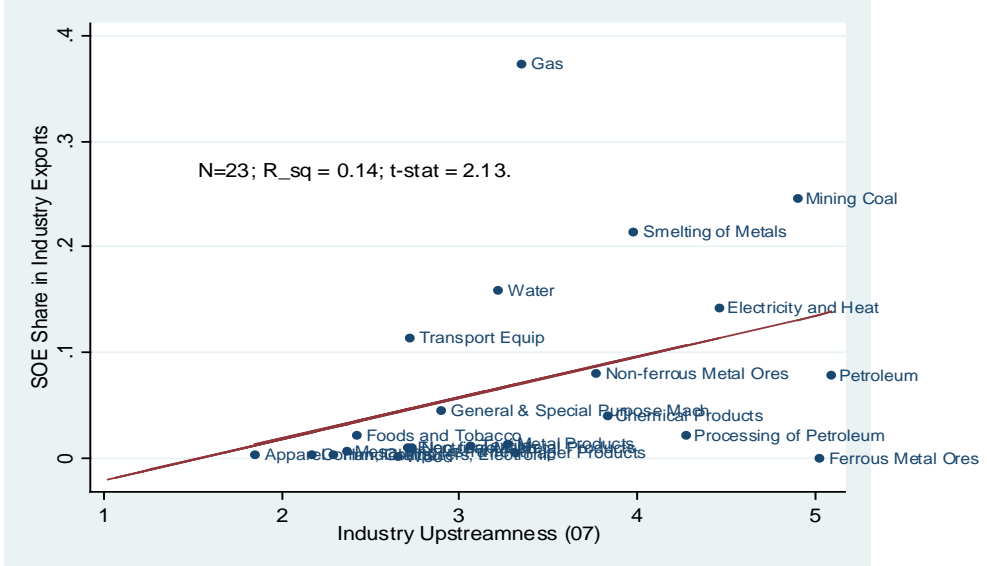


Figure 7: Share of SMEs in Sector Output versus Sector Upstreamness

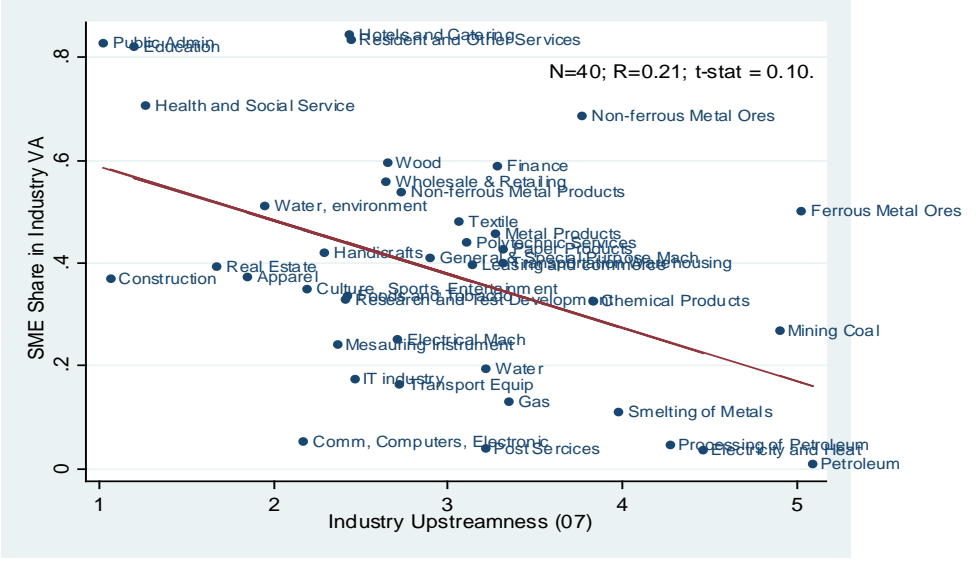

Figure 8: Share of SMEs in Sector Exports versus Sector Upstreamness

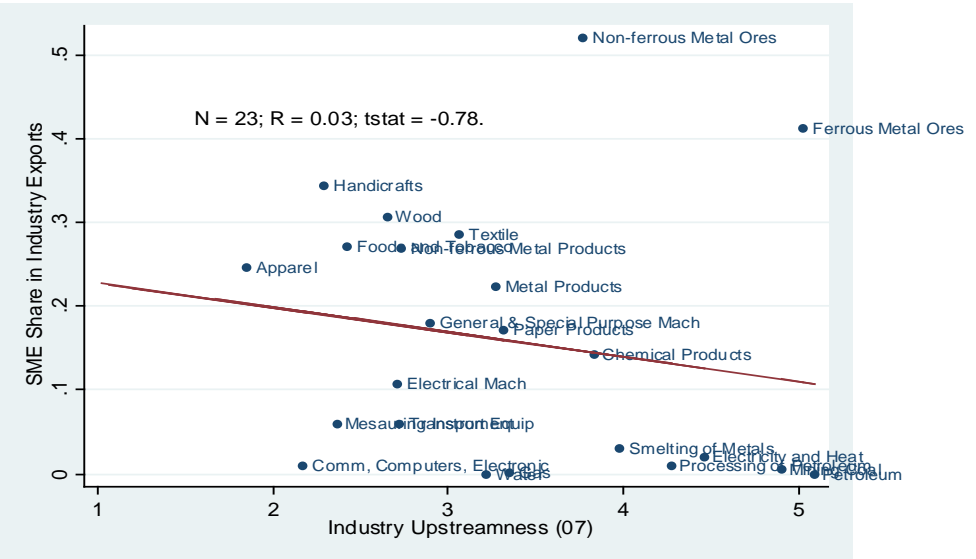

Figure 9: Upstreamness 2007 and 2010

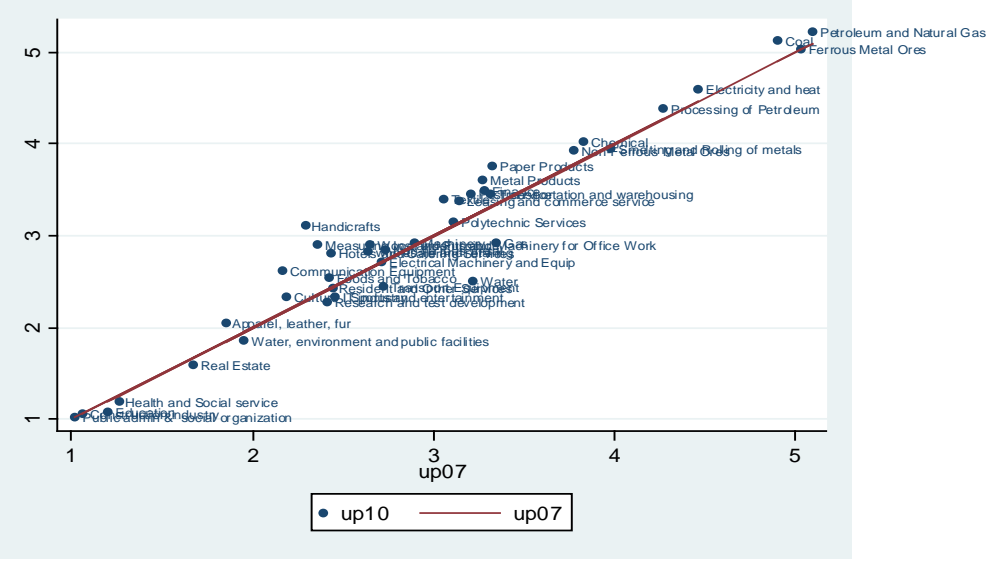

